\title{
The conditional capital asset pricing model revisited: evidence from high-frequency betas
}

Article

Accepted Version

Hollstein, F., Prokopczuk, M. and Wese Simen, C. (2020) The conditional capital asset pricing model revisited: evidence from high-frequency betas. Management Science, 66 (6). pp. 22912799. ISSN 1526-5501 doi:

https://doi.org/10.1287/mnsc.2019.3317 Available at https://centaur.reading.ac.uk/82529/

It is advisable to refer to the publisher's version if you intend to cite from the work. See Guidance on citing.

To link to this article DOI: http://dx.doi.org/10.1287/mnsc.2019.3317

Publisher: INFORMS

All outputs in CentAUR are protected by Intellectual Property Rights law, including copyright law. Copyright and IPR is retained by the creators or other copyright holders. Terms and conditions for use of this material are defined in the End User Agreement.

www.reading.ac.uk/centaur 
Central Archive at the University of Reading

Reading's research outputs online 


\title{
The Conditional CAPM Revisited: Evidence from High-Frequency Betas*
}

\author{
Fabian Hollstein ${ }^{\dagger}$, Marcel Prokopczuk ${ }^{\dagger,}$, and Chardin Wese Simen ${ }^{\ddagger}$
}

February 1, 2019

\begin{abstract}
When using high-frequency data, the conditional CAPM can explain asset-pricing anomalies. Using conditional betas based on daily data, the model works reasonably well for a recent sample period. However, it fails to explain the size anomaly as well as 3 out of 6 of the anomaly component excess returns. Using high-frequency betas, the conditional CAPM is able to explain the size, value, and momentum anomalies. We further show that high-frequency betas provide more accurate predictions of future betas than those based on daily data. This result holds for both the time-series and the cross-sectional dimensions.
\end{abstract}

JEL classification: G11, G12, C58

Keywords: Beta estimation, conditional CAPM, high-frequency data

\footnotetext{
${ }^{*}$ We are grateful to Karl Diether (the editor), an anonymous associate editor, two anonymous referees, Alexandros Kontonikas, Binh Nguyen, Björn Tharann, as well as seminar participants at the Financial Econometrics and Empirical Asset Pricing Conference in Lancaster, the World Finance Conference, and Leibniz University Hannover for providing valuable comments. Contact: hollstein@fmt.uni-hannover.de (F. Hollstein), prokopczuk@fmt.uni-hannover.de (M. Prokopczuk), and C.Wese-Simen@icmacentre.ac.uk (C. Wese Simen).

${ }^{\dagger}$ School of Economics and Management, Leibniz University Hannover, Koenigsworther Platz 1, 30167 Hannover, Germany.

${ }^{\ddagger}$ ICMA Centre, Henley Business School, University of Reading, Reading, RG6 6BA, UK.
} 


\section{Introduction}

Already shortly after its introduction by Sharpe (1964), Lintner (1965), and Mossin (1966), the unconditional Capital Asset Pricing Model (CAPM) was heavily challenged by empirical studies, e.g., Black et al. (1972). However, even though the unconditional CAPM seems to be rejected in the data, the model may well hold conditionally periodby-period. The market portfolio may be on the conditional mean-variance frontier, but not on the unconditional one (Hansen \& Richard, 1987).

In this paper, we revisit the conditional CAPM. We use a large sample of more than 2,500 stocks with both daily and high-frequency data for the period from 1996 until 2014 to empirically test whether the conditional CAPM can explain asset-pricing anomalies.

We make several contributions to the literature. First, we perform a test of the conditional CAPM following the approach of Lewellen \& Nagel (2006) for our recent sample period. We find that the conditional CAPM performs reasonably well when using daily data. Examining the anomaly component portfolios, i.e., the portfolios of small, big, growth, value, loser, and winner stocks, the model can explain the excess returns of 3 out of these 6, namely those of the big, loser, and winner stocks. Overall, the conditional CAPM is able explain the returns of the value (value minus growth) and momentum (winners minus losers) anomaly portfolios, while it fails to explain the size (small minus big) anomaly return.

Second, we go beyond the approach of the previous literature and estimate conditional betas with high-frequency (30-minute) data. We find that with high-frequency data, the conditional CAPM performs even better than based on daily data. The model can explain the excess returns of 5 out of the 6 anomaly component portfolios, namely those of the small, big, growth, value, and winner stocks. More importantly, the conditional CAPM is able to explain the returns of the size anomaly, the value anomaly, and the momentum 
anomaly portfolios. Thus, our results suggest that the inaccurate measurement of (conditional) betas weakens the empirical performance of the conditional CAPM. Once we measure betas more accurately with high-frequency data, the model performs even better than with betas based on daily data.

Third, we examine whether market-timing and volatility-timing biases documented in the previous literature can account for the magnitudes of the unconditional alphas we observe. Based on the calibrations of Lewellen \& Nagel (2006) and Boguth et al. (2011), we conclude that the magnitude of the failure of the unconditional CAPM is potentially consistent with underconditioning biases.

Our main results are robust to several tests. When using different window lengths between 1 and 12 months to estimate the conditional betas, alternative frequencies for the high-frequency beta estimator, and when accounting for a potential bias based on the use of ex-post betas we obtain qualitatively similar results. For the 6- and 12-month windows, the conditional CAPM based on high-frequency data can even explain the returns of all of the 6 component portfolios, along with those of the anomaly return portfolios.

In the final part of the paper, we examine the precision of high-frequency betas. We compare the predictive ability of the high-frequency beta estimator for future betas to that of the estimator based on daily data. We find that high-frequency betas have superior predictive power for future realized betas. Sorting stocks into 5 portfolios, we find that the root mean squared error (RMSE) is significantly lower for high-frequency betas compared to betas based on daily return data. This pattern holds for each portfolio. We find that high-frequency betas also yield a lower average RMSE than those based on daily data for alternative realized beta estimators based on lag-adjusted high-frequency or daily data. Furthermore, we find that high-frequency betas perform at the very least as well as the option-implied approach of Buss \& Vilkov (2012). We find that the predicted 
and realized betas line up very well when using high-frequency data, whereas the other estimators tend to yield high prediction errors, especially for low-beta and high-beta stocks. Furthermore, we obtain similar results when using coarser sampling frequencies. We also confirm that betas based on high-frequency data outperform those based on daily data in Mincer-Zarnowitz regressions and not only in the time-series but also in the crosssectional dimension. Finally, we obtain similar results when using the Mean Average Error (MAE) criterion as an alternative statistical loss function.

Our work relates to a large literature that tests the CAPM. Black et al. (1972) and Fama \& French (1992) find that unconditional betas are unrelated to average stock returns. However, Jagannathan \& Wang (1996) argue that the CAPM may hold period-byperiod even if it does not hold unconditionally. That is, the market portfolio could be on the conditional mean-variance frontier each period, but not on the unconditional meanvariance frontier. In this vein, Jagannathan \& Wang (1996), Lettau \& Ludvigson (2001), Lustig \& Van Nieuwerburgh (2005), and Santos \& Veronesi (2005) find empirical support for the conditional CAPM with different conditioning variables. However, Lewellen \& Nagel (2006) use daily data recorded over short windows to directly test the conditional CAPM and reject the model. We complement these studies by using betas estimated with high-frequency data. Our results suggest that the more accurate measurement of betas helps to improve the performance of the conditional CAPM.

Our paper is also related to Gilbert et al. (2014). The authors find that the CAPM pricing errors are lower when estimating betas with quarterly data compared to using daily data. However, by using quarterly data along with a long historical window of 5 years or more, one essentially gives up on trying to obtain a truly conditional estimate for beta. Our results indicate that conditional betas estimated with intraday data outperform those based on lower frequency data both economically and statistically. 
We also add to the literature on beta estimation. Buss \& Vilkov (2012), Chang et al. (2012), and Baule et al. (2016) propose different estimators that exploit the information content of option prices. Hollstein \& Prokopczuk (2016) compare these approaches and find that the hybrid estimator of Buss \& Vilkov (2012) outperforms the low-frequency historical beta estimator as well as all other approaches that use options or daily return data. We depart from these studies by exploiting high-frequency return data to more accurately estimate beta. To the best of our knowledge, we are the first to compare these approaches and show that high-frequency beta performs at least as well as the option-implied approach. Furthermore, we add to Hollstein \& Prokopczuk (2016) by evaluating different beta estimators primarily from an economic perspective, by testing the conditional CAPM.

This study uses the concept of realized beta in the spirit of Bollerslev \& Zhang (2003), Barndorff-Nielsen \& Shephard (2004), Andersen et al. (2006), Bollerslev \& Todorov (2010), and Patton \& Verardo (2012). Cenesizoglu et al. (2016) study the stocks that make up the Dow Jones Industrial Average and show that beta measured with highfrequency data yields statistically more accurate predictions than the historical estimator based on daily or monthly return data. While our results are consistent with theirs, there are important differences with our study. First, we focus on the asset-pricing implications of high-frequency beta. Second, we study a much broader cross-section of stocks. Third, we analyze the predictability for realized beta not only from a time-series perspective but also in the cross-sectional dimension.

Finally, our paper belongs to a broader research area analyzing the benefits of highfrequency data. Andersen \& Bollerslev (1998) highlight the importance of intraday data for accurately measuring realized volatility. Andersen et al. (2005b) demonstrate the impact of measurement error in the variance of an asset on the classical Mincer-Zarnowitz 
regressions. Patton (2011) studies the impact of measurement error on the ranking of different volatility forecasting models. Amaya et al. (2015) establish the importance of intra-day data for the accurate measurement of skewness and kurtosis. We complement these studies by showing that high-frequency data matter for the estimation of betas. Based on this finding, our recommendation to the academic and professional literature is to generally use high-frequency data for beta estimation whenever possible.

The remainder of this paper is organized as follows. Section II describes our data set and methodology and presents summary statistics for the different beta estimators. In Section III, we test the conditional CAPM. Section IV examines the precision of highfrequency betas. Finally, Section V concludes.

\section{Data and Methodology}

\section{A Data}

Our data set covers U.S. stocks for the sample period from January 1996 to December 2014. We use daily and monthly prices and returns as well as data on dividend payments and shares outstanding from the Center for Research in Security Prices (CRSP). In addition, we collect high-frequency price data from the Thomson Reuters Tick History (TRTH) database. ${ }^{1}$ We use all stocks traded on the New York Stock Exchange (NYSE), the American Stock Exchange (AMEX), and the National Association of Securities Dealers Automated Quotations (NASDAQ) that are classified as ordinary common shares (CRSP share codes 10 or 11) and for which both daily and high-frequency data are available. Following Amihud (2002) and Zhang (2006), we exclude very illiquid stocks. To be more precise, we expunge firm-month observations with prices below 1 U.S. dollar

\footnotetext{
${ }^{1}$ The starting date of our study is determined by the need to have high-frequency data. The TRTH database does not start until the beginning of 1996.
} 
or a market capitalization below 10 million U.S. dollars (Cohen et al., 2002; Hou \& Loh, 2016). On average, the stocks for which high-frequency data are available represent $87 \%$ of the entire market capitalization of eligible U.S. stocks.

In order to process the final high-frequency data set, we follow the data-cleaning steps outlined in Barndorff-Nielsen et al. (2009). First, we use only data with a time stamp during the exchange trading hours, i.e., between 9:30AM and 4:00PM Eastern Standard Time. Second, we remove recording errors in prices. To be more specific, we filter out prices that differ by more than 10 mean absolute deviations from a rolling centered median of 50 observations. Afterwards, we assign prices to every 5-minute interval using the most recent entry recorded that occurred at most one day before. Finally, we follow Bollerslev et al. (2016) and supplement the TRTH data with data on stock splits and distributions from CRSP to adjust the TRTH overnight returns. To guard against the potential effects of non-trading in smaller stocks (Gorodnichenko \& Weber, 2016), for our main tests we rely on a 30-minute frequency for our main analysis.

The Options data set comes from IvyDB OptionMetrics. We obtain data from the Volatility Surface that directly provides implied volatilities over standardized times to maturity for certain levels of delta. ${ }^{2}$ We select out-of-the-money (OTM) options, namely puts with deltas larger than -0.5 and calls with deltas smaller than 0.5 . To compute the model-free option-implied moments, we use the formulas provided by Bakshi et al. (2003). A more detailed outline of the procedure is provided in the Technical Appendix. Data on the interest rate term structure come from the IvyDB zero curve file.

We collect balance sheet data from the Compustat database. The book equity of each stock is computed as stockholders' equity plus balance sheet deferred taxes and investment

\footnotetext{
${ }^{2}$ IvyDB uses a kernel smoothing algorithm that generates standardized options only "if there exists enough option price data on that date to accurately interpolate the required values". For more details refer to the IvyDB technical document.
} 
tax credit plus post-retirement benefit liabilities minus the book value of preferred stock. Data on the risk-free (1-month Treasury Bill) rate are from Kenneth French's data library.

\section{B Beta Estimation}

Historical Beta We consider historical estimates (HIST) following, e.g., Fama \& MacBeth (1973), regressing an asset's daily excess return on a constant and the (contemporaneous) market excess return:

$$
\beta_{j, t}^{\mathrm{HIST}}=\frac{\operatorname{cov}\left(r_{j}-r_{f}, r_{M}-r_{f}\right)}{\operatorname{var}\left(r_{M}-r_{f}\right)}
$$

where $\beta_{j, t}^{\mathrm{HIST}}$ denotes the estimator for the historical beta of asset $j$ using data from time $t-k$ to $t . \quad k$ is the length of the estimation window. $r_{j}$ is the vector of returns on asset $j, r_{M}$ denotes the return-vector of the market, and $r_{f}$ is the vector of the risk-free rate. All returns are observed up to time $t$. Alternatively, $\operatorname{HIST}^{(l)}$ denotes a Dimson (1979)-adjusted historical estimator, which we obtain through the following regression:

$$
\begin{aligned}
r_{j, \tau}-r_{f, \tau}= & \alpha_{j, t}+\beta_{j, t}^{(0)}\left(r_{M, \tau}-r_{f, \tau}\right)+\beta_{j, t}^{(1)}\left(r_{M, \tau-1}-r_{f, \tau-1}\right) \\
& +\beta_{j, t}^{(2)}\left(\sum_{n=2}^{l} r_{M, \tau-n}-r_{f, \tau-n}\right)+\epsilon_{j, \tau} .
\end{aligned}
$$

We incorporate $l=1$ up to $l=4$ lagged returns. In the case $l=1$, the term associated

with $\beta_{j, t}^{(2)}$ drops. The estimator for beta is then $\beta_{j, t}^{\operatorname{HIST}^{(l)}}=\sum_{i=0}^{\min (2, l)} \beta_{j, t}^{(i)}$, where $\min (\cdot)$ is the minimum operator.

Realized Beta Following Andersen et al. (2006), we use realized beta $\left(\mathrm{HF}_{\text {freq }}\right)$. We utilize intra-day high-frequency (log-)returns, sampled at intervals of freq minutes to 
estimate: ${ }^{3}$

$$
\beta_{j, t}^{\mathrm{HF}}=\frac{\sum_{\tau=1}^{N} r_{j, \tau} r_{M, \tau}}{\sum_{\tau=1}^{N} r_{M, \tau}^{2}},
$$

where $r_{j, \tau}$ and $r_{M, \tau}$ refer to the return of asset $j$ and the market return at time $\tau$, respectively. $N$ is the number of high-frequency return observations during the time period under investigation. Note that we use realized beta both as estimator for high-frequency historical beta $\left(\mathrm{HF}_{\text {freq }}\right)$ and for the ex-post evaluation of estimators $\left(\beta_{j, t, T}^{\mathrm{R}}=\beta_{j, t}^{\mathrm{HF}}\right.$, using data between $t$ and $T=t+m$, with $m$ denoting the length of the evaluation horizon).

An important point relates to the sampling frequency (freq). As Patton \& Verardo (2012) point out, there is a delicate trade-off. On the one hand, using low-frequency data could result in noisy estimates of beta (Andersen et al., 2005a). On the other, pushing the analysis to a very high frequency introduces a number of microstructure issues (Scholes \& Williams, 1977; Epps, 1979). We focus our main analysis on a sampling frequency of 30 minutes. One might worry that the sampling frequency we use is quite high and that stocks may not have synchronous trading times, introducing a bias in the estimation of beta. To address this concern, we also use an estimator that accounts for lag effects, as in Dimson (1979). ${ }^{4}$ In addition, we use several alternative sampling frequencies, including 75 and 130 minutes and obtain similar results.

Hybrid (Option-Implied) Beta We also consider the hybrid estimator of Buss \& Vilkov (2012) (BV), which has been shown by Hollstein \& Prokopczuk (2016) to yield the

\footnotetext{
${ }^{3}$ Note that the formula for realized beta makes use of the expanded formula for the variance, neglecting both the drift term and the risk-free rate. Andersen et al. (2006) note that the effect of the drift term vanishes as the sampling frequency is reduced which effectively "annihilates" the mean. This view is supported by empirical facts, e.g., the average 30-minute return of the S\&P 500 index amounts to only $0.0017 \%$. Similarly, the average daily riskless interest rate during our sample period amounts to $0.01 \%$, which is equivalent to an average risk-free rate as low as $0.0007 \%$ over 30 -minute intervals, indicating that it can indeed be neglected.

${ }^{4}$ In this case, we compute the realized beta with respect to several lagged market returns and simply sum up the contemporaneous and lagged realized betas.
} 
most accurate predictions among models relying on daily or monthly return data. Essentially, the approach combines model-free option-implied volatilities and historical correlations to estimate beta. Buss \& Vilkov (2012) use (i) the identity that the implied variance of the market index has to be the same as the implied variance of the value-weighted portfolio of all index constituents and (ii) a technical condition that maps physical correlations $\left(\rho_{j i, t}^{\mathbb{P}}\right)$ into risk-neutral correlations $\left(\rho_{j i, t}^{\mathbb{Q}}\right)$, namely $\rho_{j i, t}^{\mathbb{Q}}=\rho_{j i, t}^{\mathbb{P}}-\alpha_{t}\left(1-\rho_{j i, t}^{\mathbb{P}}\right) \cdot{ }^{5}$ Combining these two relations and solving for $\alpha_{t}$, the authors recover implied correlations. Thus, a beta estimate under the risk-neutral probability measure is obtained by:

$$
\beta_{j, t}^{\mathrm{BV}}=\frac{\sigma_{j, t, T}^{\mathbb{Q}} \sum_{i=1}^{N} \omega_{i, t} \sigma_{i, t, T}^{\mathbb{Q}} \rho_{j i, t}^{\mathbb{Q}}}{\left(\sigma_{M, t, T}^{\mathbb{Q}}\right)^{2}}
$$

where $\sigma_{j, t, T}^{\mathbb{Q}}$ and $\sigma_{M, t, T}^{\mathbb{Q}}$ denote the option-implied volatilities at time $t$ from options of asset $j$ and the market index, respectively. The implied volatilities needed for the approach are extracted from options whose time to expiration $T-t$ matches the evaluation horizon $m$. Thus, for our main tests, we use options with a time-to-maturity of 30 days. $\omega_{i, t}$ denotes the weight of asset $i$ in the market index at time $t$. We use all daily returns observed in the measurement period to obtain the correlations needed for the standard BV estimator.

We also use high-frequency correlations, estimated with 30-minute data, combined with option-implied volatility $\left(\mathrm{BV}_{30}\right)$. By comparing $\mathrm{BV}$ and $\mathrm{BV}_{30}$ we can shed light on the value of high-frequency data for the hybrid estimator. Notice that because of condition (i), we need the full correlation matrix of all index constituents. Therefore, it is not clear whether using high-frequency data is beneficial since the problem of infrequent and non-synchronous trading is likely much more severe than for the historical realized

\footnotetext{
${ }^{5}$ The technical condition is motivated by several points. First, the correlation needs to be between -1 and 1. Secondly, the correlation matrix must be positive (semi-) definite. Thirdly, the correlation risk premium must be consistent with empirical observations, namely that implied correlations are higher than realized correlations and that the correlation risk premium $\rho_{j i, t}^{\mathbb{P}}-\rho_{j i, t}^{\mathbb{Q}}$ is higher for stocks with low correlations under the physical measure. For more details, refer to Buss \& Vilkov (2012).
} 
beta estimator where for each stock only one correlation, i.e., that of an asset with the market, has to be estimated.

\section{Summary Statistics and Correlation Analysis}

Table 1 reports summary statistics on the different beta estimation approaches. ${ }^{6}$ The number of total observations is substantially higher for all historical and high-frequency estimators compared to $\mathrm{BV}$ and $\mathrm{BV}_{30}$ mainly because the hybrid estimator can only be implemented for the constituents of the S\&P 500 index at each point in time, while we can estimate the historical and high-frequency betas independently of whether the stock is part of a market index or not.

We first examine the value-weighted average beta over all stocks $\left(\operatorname{Mean}_{v w}\right)$. This quantity should be equal to 1 when examining a complete market index. Since we do not examine a full market index, but a much broader universe than the S\&P 500 stocks, this condition is not binding, but it can serve as a reference value to assess whether the beta estimates are reasonable. We find that the value-weighted averages for all approaches are close to 1. For HIST, for example, the value-weighted average beta is 1.00. Adding lags in $\operatorname{HIST}^{(1)}$ and $\operatorname{HIST}^{(2)}$, the value-weighted average increases slightly to 1.02 . However, adding lags increases the standard deviation and decreases the $\mathrm{AR}(1)$ coefficient. Both observations indicate that adding lagged betas substantially increases the measurement error in HIST. Noise in the estimator naturally increases the standard deviation and creates an attenuation bias in the $\mathrm{AR}(1)$ coefficient. Since the value-weighted average of HIST is 1.00, there is little evidence to suggest that HIST is systematically biased. Thus, we focus our main discussion on the estimator without lag-adjustment.

\footnotetext{
${ }^{6}$ Note that to keep the presentation manageable, we select only one estimation window length for the estimators. That is, according to the optimization that becomes relevant in Section IV.A we use 12 months for all HIST estimators and 6 months for the HF and BV estimators. The summary statistics for alternative sampling windows are very similar.
} 
On the other hand, the value-weighted average beta from high-frequency estimators is just under 1 . For our main estimator $\mathrm{HF}_{30}$, the value-weighted beta reaches 0.95 . For the lower 75-minute and 130-minute frequencies, this quantity amounts to 0.96. These figures deliver some indication that infrequent and non-synchronous trading may bias beta toward zero for some stocks. On the other hand, adding only one lag to $\mathrm{HF}_{30}\left(\mathrm{HF}_{30}^{(1)}\right)$,

the value-weighted average rises to 0.99 . With 5 lags $\left(\mathrm{HF}_{30}^{(5)}\right)$, the value-weighted average is 1.02. Similar to HIST, when adding lags, the standard deviation of $\mathrm{HF}_{30}$ increases and the $\mathrm{AR}(1)$ coefficient decreases, which points toward increased measurement error when adding lags. Nevertheless, since it is possible that there is a bias in $\mathrm{HF}_{30}$, we focus our main discussion on both $\mathrm{HF}_{30}$ and $\mathrm{HF}_{30}^{(1)}$. Overall, the potential downward-bias in high-frequency betas does not seem to be a big issue, but we are careful to examine the robustness of all our main results to using lag-adjusted estimators.

Table 1 also presents the average firm-level correlation coefficients for different estimators. We observe a correlation of 0.78 between the historical daily and the 30 -minute high-frequency estimator. These figures indicate that the two estimators may to some extent contain different information. Since for $\mathrm{BV}$ and $\mathrm{BV}_{30}$ only the input to obtain correlations differs, the correlation of $\mathrm{BV}$ and $\mathrm{BV}_{30}$ is higher and amounts to 0.89 .

\section{The Conditional CAPM Revisited}

\section{A Empirical Setup}

We start our main empirical analysis by exploring the ability of the conditional CAPM to explain the main empirical asset pricing anomalies. Specifically, we set out to examine the following questions: Can the new high-frequency beta estimates allow us a second look at the conditional CAPM? Can high-frequency estimates of beta help explain why small 
firms generally outperform large firms? Can we explain the value effect when using highfrequency betas? Can the conditional CAPM explain why past winner stocks generally outperform past loser stocks?

To perform the analysis, we follow the approach suggested by Lewellen \& Nagel (2006) and use direct estimates for conditional betas. Along with each conditional beta estimate, we obtain an estimate for the conditional alpha. We thus partition the entire sample used for unconditional tests allowing for time-variation in betas. For our main empirical tests, we use quarterly non-overlapping windows. For each of these quarterly windows, we obtain conditional alphas and betas for each of the anomaly portfolios. Using the timeseries of conditional alphas, we can perform a direct test of the conditional CAPM by testing whether the average alpha is significantly different from zero or not. We assess the statistical significance using robust Newey \& West (1987) standard errors with 4 lags.

We test the model for different anomaly portfolios. For all anomaly portfolios, we utilize NYSE breakpoints and obtain the conditional alphas and betas as value-weighted averages of the respective conditional alphas and betas of the stocks in that portfolio. We construct size and value portfolios following Lewellen \& Nagel (2006). In order to obtain the book-to-market ratio for each stock, we use the firm's most recent observation for the book value (assuming the book equity from the previous year becomes available at the end of June in the current year) and divide it by the market capitalization at the end of December of the previous fiscal year. Thus, the book-to-market ratio changes at the end of June each year using new information both on the book equity and the market capitalization for the previous fiscal year. Each month, we sort the stocks independently into 25 size-B/M portfolios and base our tests on combinations of these portfolios: $\mathrm{S}$ (Small) is the average of the 5 low-market-cap portfolios and B (Big) is the average of the 5 high-market-cap portfolios while $\mathrm{S}-\mathrm{B}$ is their difference. Similarly, G (Growth) is 
the average of the 5 low-book-to-market portfolios and $\mathrm{V}$ (Value) is the average of the 5 high-book-to-market portfolios. $\mathrm{V}-\mathrm{G}$ is the difference between the Value and Growth portfolios. For momentum, we sort the stocks into 10 portfolios based on their prior 12month return, while skipping the most recent 1 month (Jegadeesh \& Titman, 1993). L (Losers) and W (Winners) are the bottom and top deciles. W-L is the difference between the Winners and Losers portfolios.

\section{B The Unconditional CAPM}

We present the empirical results in Table 2. To set the stage, we first present the results of the unconditional CAPM. That is, we regress the monthly portfolio excess returns on a constant and that of the S\&P 500 market index. We find that the portfolio of small stocks has a significant alpha of $0.65 \%$ per month. Thus, the unconditional CAPM is not able to explain the return on small stocks. For big stocks, the model works substantially better: the portfolio of big stocks has an alpha of $0.01 \%$, which is not statistically significant. We observe an unconditional size effect with a S-B alpha of $0.63 \%$, which is significant at $5 \%$. Thus, the unconditional CAPM fails to explain the return of the size anomaly portfolio.

For the value anomaly, we find a significant alpha for the growth portfolio of $0.46 \%$ and an insignificant alpha for the value portfolio of $0.42 \%$. Thus, the unconditional CAPM can explain the return of the portfolio of value stocks, but not that of growth stocks. In total, there is no significant difference between the value and growth alphas. For momentum, we detect an insignificant alpha of $-0.57 \%$ per month for the loser portfolio and a significant alpha of $0.49 \%$ for the winner portfolio. Thus, the unconditional CAPM can explain the return of the portfolio of loser stocks, but fails with the portfolio of winner stocks. Finally, there is a significant alpha of momentum anomaly portfolio of $1.06 \%$ per month.

The significant size effect is consistent with results in the previous literature (e.g., 
Banz, 1981 and Fama \& French, 1992). The results for the value anomaly are also consistent with the recent empirical literature, showing that the value effect is substantially attenuated for the more recent period (e.g., Hou et al., 2015; Bollerslev et al., 2016; Hou et al., 2018). The positive momentum effect is consistent with Jegadeesh \& Titman (1993) and Goyal \& Jegadeesh (2018), among many others.

To further validate that the results of our sample are reasonable and representative for the full NYSE/AMEX/NASDAQ sample, we compute the correlations of the hedge portfolio returns resulting from our sorts and those that result from using the corresponding portfolio returns available from Kenneth French's webpage. That is, we use the 25 Fama-French portfolios sorted on size and book-to-market as well as the 10 portfolios sorted on momentum to obtain full NYSE/AMEX/NASDAQ sample hedge portfolio returns in a similar vein as for our main results. We obtain a correlation of $71 \%$ between S-B based on the Fama-French portfolios and our S-B returns and a correlation of 87\% between $\mathrm{H}-\mathrm{L}$ based on the Fama-French portfolios and our $\mathrm{H}-\mathrm{L}$ portfolio return. For momentum, we obtain a correlation of $96 \%$ with the $\mathrm{W}-\mathrm{L}$ hedge portfolio return based on the Fama-French portfolios. Thus, even though we limit our sample to stocks with available high-frequency data, the constructed portfolios do not seem to be materially different.

\section{The Conditional CAPM With Daily Data}

Second, we test whether the conditional CAPM based on daily data is able to explain the size, value, and momentum anomalies. The results of this analysis are also presented in Table 2. For HIST, we detect a statistically significant alpha for the portfolio of small stocks of $0.79 \%$ per month. The conditional CAPM with daily data is thus not able to explain the return on small stocks. For the portfolio of big stocks, the alpha amounts to 
$0.10 \%$ per month, which is not statistically significant. Hence, small stocks seem to pose a much stronger challenge for the model than do big stocks.

For the S-B portfolio, we detect a significantly positive alpha of $0.69 \%$ per month. The results for the Small, Big, and S-B portfolios are broadly consistent with those of Lewellen \& Nagel (2006). In Table 3 of their paper, for example, the alpha of the S-B portfolio with quarterly windows amounts to $0.42 \%$ per month with a standard error of 0.22. These numbers correspond to a $t$-statistic of 1.91 , which is marginally insignificant at $5 \%$ (the criterion for boldface printing in their table), but it is clearly significant at $10 \%$. For our sample, the size anomaly is even somewhat stronger and the conditional CAPM cannot explain this anomaly when using daily data.

Turning to the value anomaly, we obtain a statistically significant alpha of $0.60 \%$ per month for growth stocks. For the portfolio of value stocks, the corresponding figure amounts to $0.52 \%$ per month, which is also statistically significant. Thus, the conditional CAPM with daily data cannot explain the returns of both growth and value stocks. The V-G portfolio has an insignificant alpha, consistent with that of the unconditional CAPM. In this case, the results for our sample period differ from those of Lewellen \& Nagel (2006), who find a significant V-G alpha of the conditional CAPM for the 1964-2001 period. ${ }^{7}$

Finally, examining the momentum anomaly, we find that for HIST neither the loser nor the winner portfolio generate a significant alpha. Thus, the conditional CAPM can explain the returns of both past losers and past winners when using daily return data. The alpha of the $\mathrm{W}-\mathrm{L}$ portfolio amounts to $0.16 \%$ per month, which is not statistically significant.

Thus, overall, we find that the conditional CAPM works quite well for the recent sample period. With daily data, the conditional CAPM can explain the returns of big,

\footnotetext{
${ }^{7}$ Using the same stocks and sample period as in Lewellen \& Nagel (2006), we obtain similar results as the original authors.
} 
loser, and winner stocks, as well as the value and momentum anomaly portfolios, but it fails to explain the returns of small, growth, and value stocks, as well as the size anomaly portfolio.

Adding lags in the estimation of beta does not alter these conclusions. $\operatorname{HIST}^{(1)}$ and $\operatorname{HIST}^{(2)}$ yield statistically significant alphas in exactly the same cases as HIST. With daily data and a lag-adjustment in the beta estimation, the conditional CAPM can explain the value and momentum anomalies, but not the size anomaly.

To make sure that these results are not driven by the use of a subsample, which relies on stocks for which we have high-frequency data, in untabulated results, we also repeat the previous analysis for the full NYSE/AMEX/NASDAQ sample of eligible stocks for our sample period. We obtain very similar results. The S-B unconditional return is slightly smaller, but the conditional CAPM based on daily data cannot explain the size anomaly. The S-B alpha of HIST amounts to $0.69 \%$ per month. However, the conditional CAPM using daily data can explain the value and size anomalies. The $\mathrm{V}-\mathrm{G}$ and $\mathrm{W}-\mathrm{L}$ alphas are of similar magnitude as for our sample. Similar to our main sample, the average alphas and betas change only marginally when using lag-adjusted betas.

\section{The Conditional CAPM With High-Frequency Data}

In a next step, we examine the performance of the conditional CAPM when using betas based on the potentially more informative high-frequency data. We present the analysis also in Table 2. With betas estimated from high-frequency data $\left(\mathrm{HF}_{30}\right)$, the alpha of the portfolio of small stocks amounts to only $0.13 \%$ per month, which is substantially smaller than the $0.79 \%$ observed for HIST. The alpha of the portfolio of big stocks amounts to $-0.06 \%$ per month. Thus, using high-frequency data, the conditional CAPM can explain the returns of both small and big stocks. 
The average alpha of the combined S-B portfolio is $0.19 \%$ per month, which is also not statistically significant. Hence, the conditional CAPM based on high-frequency data can explain the size anomaly. $\mathrm{HF}_{30}$ seems to substantially better capture the time-variation in betas of small and big stocks.

One may argue that it is not very surprising that $\mathrm{HF}_{30}$ can explain the size anomaly since the betas of small and infrequently traded stocks are likely biased downward when using high-frequency data because of asynchronous trading times with the market. However, this argument does not square well with the empirical evidence. The literature, and also our tests based on HIST, typically detects an outperformance of small over big stocks. If small stocks tend to have lower betas when using high-frequency data this, in turn, would imply that these stocks have higher conditional alphas on average. However, what we find is the exact opposite. The small stock portfolio has a substantially lower average conditional alpha for $\mathrm{HF}_{30}$ compared to HIST. Thus, it is very unlikely that a potential downward-bias in high-frequency betas drives these results. Thus, the fact that the conditional CAPM can explain the size anomaly with high-frequency but not with daily data points toward a superior information content of high-frequency betas.

The alpha of the portfolio of growth stocks amounts to $0.01 \%$ per month and that of value stocks to $0.13 \%$ per month. Both alphas are smaller in magnitude for $\mathrm{HF}_{30}$ than for HIST and are not statistically significant. Thus, as opposed to when using daily data, with high-frequency data, the conditional CAPM can explain the returns of growth and value stocks. We also find that the conditional CAPM with high-frequency data is able to explain the return of the value anomaly portfolio: the $\mathrm{V}-\mathrm{G}$ alpha amounts to an insignificant $0.12 \%$ per month.

Finally, for momentum, we detect a monthly alpha for the loser portfolio of $-0.86 \%$ per month, which is significant at $10 \%$. Thus, the conditional CAPM with high-frequency data 
has problems in explaining the returns of past loser stocks. For the winner portfolio, the alpha is $-0.38 \%$ per month, which is not statistically significant. Thus, in explaining the returns of past winner stocks, the conditional CAPM with high-frequency data performs similarly well as with daily data. The $\mathrm{W}-\mathrm{L}$ portfolio yields an insignificant alpha of 0.48\% per month. Hence, with high-frequency data, the conditional CAPM can overall also explain the return of the momentum anomaly portfolio.

Using a lag-adjustment for the high-frequency betas does not qualitatively change our results. The conditional CAPM with $\mathrm{HF}_{30}^{(1)}$ and $\mathrm{HF}_{30}^{(5)}$ can explain the returns of the size, value, and momentum anomaly portfolios.

\section{E Underconditioning Bias}

Following Lewellen \& Nagel (2006) and Boguth et al. (2011), we now examine the potential bias that could be introduced by underconditioning, i.e., by using the unconditional CAPM instead of the conditional CAPM when betas indeed vary over time. Boguth et al. (2011) show that if the conditional alphas are uncorrelated with the market excess return, the bias in unconditional alphas, i.e., the difference between the unconditional alpha $\left(\alpha_{j}^{\text {unc }}\right)$ and the average conditional alpha $\left(\bar{\alpha}_{j}^{\text {cond }}\right)$, can be described as:

$$
\begin{aligned}
\alpha_{j}^{\text {unc }}-\bar{\alpha}_{j}^{\text {cond }}= & \underbrace{\left(1+\frac{\bar{R}_{M}^{2}}{\sigma_{M}^{2}}\right) \operatorname{cov}\left(\beta_{j, t}, \mathbb{E}_{t}\left(R_{M, t}\right)\right)-\left(\frac{\bar{R}_{M}}{\sigma_{M}^{2}}\right) \operatorname{cov}\left(\beta_{j, t}, \mathbb{E}_{t}\left(R_{M, t}^{2}\right)\right)}_{\text {market-timing bias }} \\
& \underbrace{-\left(\frac{\bar{R}_{M}}{\sigma_{M}^{2}}\right) \operatorname{cov}\left(\beta_{j, t}, \sigma_{M, t}^{2}\right)}_{\text {volatility-timing bias }},
\end{aligned}
$$

where $R_{M, t}$ denotes the market excess return, i.e., $r_{M, t}-r_{f, t}, \bar{R}_{M}$ is the average market excess return and $\sigma_{M}^{2}$ is the unconditional variance of the market excess return and $\sigma_{M, t}^{2}$ is its conditional expectation. 
The underconditioning bias thus consists of a market-timing and a volatility-timing bias. The market-timing bias results from the covariation of conditional betas with the expected market excess return or the expected squared market excess return and reflects the fact that betas likely vary with the business cycle (Jagannathan \& Wang, 1996). The volatility-timing bias results from the negative covariation of conditional betas with the conditional volatility of the market, which appears to be particularly pronounced for momentum, where the current market return predicts both future betas and future market volatility (Grundy \& Martin, 2001; Boguth et al., 2011).

Lewellen \& Nagel (2006) argue that the market-timing bias is small in magnitude. They examine this bias for different sets of parameters and obtain a bias that is "typically less than 0.20\%" per month "with a maximum of 0.35\%". Boguth et al. (2011) find that the volatility-timing bias can be substantially larger than the market-timing bias. For the parameter sets used in their paper, the volatility timing bias reaches values between $0.10 \%$ per month and $1.01 \%$ per month. For the portfolios in our sample, the alphas in absolute terms range between $0.01 \%$ per month for the portfolio of big stocks and $1.06 \%$ per month for the momentum anomaly portfolio, while most returns are below $0.7 \%$ per month in absolute terms. Thus, the magnitude of the unconditional returns we observe is potentially consistent with an underconditioning bias. For the most extreme parameter calibrations, even an unconditional alpha as high as the $1.06 \%$ for the momentum anomaly portfolio is still within a possible range. ${ }^{8}$

\section{F Alternative Window Lengths}

For the main tests of the conditional CAPM in Sections III.C and III.D, we use a 3-month window to estimate conditional alphas and betas. However, the window length

\footnotetext{
${ }^{8}$ Unfortunately, it is not possible to pin down the bias for one portfolio to exact numbers since the factors that drive these biases are latent and not observable.
} 
involves a trade-off: on the one hand, a shorter window might improve the model's performance because it allows for greater variation in beta. On the other, longer windows could increase the precision of the conditional alpha and beta estimates and improve the model performance in this way.

Hence, we examine alternative window lengths of 1 month, 6 months, and 12 months in Table 3. We only report the results for our main estimators HIST, $\mathrm{HF}_{30}$, and $\mathrm{HF}_{30}^{1}$. As the table shows, these changes do not affect our main conclusions.

\section{G Alternative Frequencies}

Next, we examine the impact of alternative sampling frequencies of the high-frequency estimator on our results. In Table 4, we examine estimators based on 5-, 75-, and 130minute data with and without lags. For all these estimators, we obtain qualitatively similar results as for $\mathrm{HF}_{30}$ : the conditional CAPM based on high-frequency data can explain the size, value, and momentum anomalies.

\section{H Alternative Conditioning Approaches}

Boguth et al. (2011) caution that one might introduce a bias in the analysis since the beta estimates used for the computation of the conditional alpha are not available to investors ex-ante, before they invest. To check whether our results are affected by such a bias, we repeat the previous analysis using 3 different alternative approaches. First, we

simply use lagged betas as proxies for future betas. Second, we estimate a regression of the form:

$$
\beta_{j, t}=a_{j}+b_{j} \beta_{j, t-1}+\epsilon_{j, t},
$$


where $\beta_{j, t}$ is the beta for time $t$ of one approach. We then use $\beta_{j, t}^{\text {instr }}=\hat{a}_{j}+\hat{b}_{j} \beta_{j, t-1}$ instead of $\beta_{j, t}$ to compute the conditional alphas. We use two variations of this approach: one that uses the full sample as in Boguth et al. (2011) and one that would be implementable in real-time and uses only data up to time $t$ with an expanding window initialized with a 36-month window.

We present the results of these approaches in Table 5. The results are very similar to our benchmark findings. We find that the conditional CAPM based on high-frequency data still explains the size, value, and momentum anomalies in all three cases.

\section{The Precision of High-Frequency Betas}

Section III shows that the use of high-frequency data can improve the performance of the conditional CAPM. This section explores whether high-frequency betas provide more accurate forecasts for future betas than those based on daily return data. We examine this by evaluating the predictability of HIST and $\mathrm{HF}_{30}$ for future realized betas. We start the analysis by picking the optimal estimation period for the estimators and then examine the estimation accuracy using root mean squared prediction errors, Mincer-Zarnowitz regressions, as well as cross-sectional tests.

\section{A Estimation Period}

We perform an out-of-sample evaluation of beta estimation precision. At the end of each month, we use all observations available during the measurement period to obtain estimates for beta and evaluate these estimates in a separate evaluation period. We use a 1-month evaluation period. In order to conduct a fair comparison, we first identify the best estimation window for each estimator. By taking this step, we ensure that the 
competing models are put on an equal footing. ${ }^{9}$ We consider various estimation windows of $1,3,6$, and 12 months. We then proceed as follows. We examine the average RMSEs of the estimators for each measurement window. We obtain the RMSE as follows:

$$
\mathrm{RMSE}=\sqrt{\frac{1}{n} \sum_{t=1}^{n}\left(\beta_{t, T}^{\mathrm{R}}-\beta_{t}\right)^{2}},
$$

where $n$ is the number of out-of-sample observations. $\beta_{t, T}^{R}$ is the realized beta in the period ranging from $t$ to $T$, and $\beta_{t}$ denotes an estimate for beta. For HIST, we find that the lowest average RMSE is obtained for a 12-month estimation window. For $\mathrm{HF}_{30}$, BV, and $\mathrm{BV}_{30}$, a 6-month estimation period turns out to be best. Thus, in the following we stick to these measurement periods for our estimators.

The shorter optimal estimation window for $\mathrm{HF}_{30}$ delivers a first indication that highfrequency data can help resolve the trade-off between conditionality of the estimates and a large sample which improves the statistical properties of the estimator. For example for HIST, we need a longer estimation window to reduce the measurement error in the estimates and thereby inevitably lose conditionality.

To ensure a fair comparison, for each of the following analyses, we only use stockmonth observations that are available for all estimators considered in that analysis.

\section{B Estimation Accuracy}

To perform the analysis, we follow the approach of Fama \& MacBeth (1973) and Hollstein \& Prokopczuk (2016). Hence, we first sort stocks into 5 portfolios according to their estimate of HIST 12 months ago, thereby ensuring that we do not sort on the

\footnotetext{
${ }^{9}$ We thank an anonymous referee for suggesting this.
} 
current measurement error of either of the approaches. ${ }^{10}$

To examine the out-of-sample estimation accuracy of the different approaches, we use the RMSE criterion of Equation (7), a loss function commonly applied in the literature. We rely on the RMSE criterion since it is shown that it is robust to the presence of (mean zero) noise in the evaluation proxy while other commonly employed loss functions are not (Patton, 2011). In Section IV.F, we also examine the Mean Absolute Error (MAE) criterion as an alternative.

We test for significance in RMSE using the modified Diebold-Mariano test as proposed by Harvey et al. (1997) and for significance in root median squared error (RMedSE) employing the non-parametric Wilcoxon signed rank test. ${ }^{11}$ The results are provided in Panel A of Table 6. In parentheses, we report the share of portfolios, for which a difference in RMSE or RMedSE is statistically significant at 5\%. In general, the results for the RMedSE and its significance are similar to those for the RMSE. Hence, in discussing our results, we mostly focus on the RMSE.

We find that HIST yields an average RMSE of 0.135. The corresponding figure for $\mathrm{HF}_{30}$ is lower by almost one third, amounting to 0.095. The RMSE of $\mathrm{HF}_{30}$ is significantly lower than that of HIST for each of the 5 portfolios. Thus, the superior economic value of $\mathrm{HF}_{30}$ appears to be linked to its superior predictive power for future realized betas. For both HIST and $\mathrm{HF}_{30}$, the lag-adjustments increase the RMSE.

One might argue that the realized beta based on 30-minute data, which we use in Panel A, could be downward-biased without lag-adjustment. Therefore, we repeat the previous analysis using realized beta with 1 lag (Panel B of Table 6) and with realized

\footnotetext{
${ }^{10}$ For the stocks, for which we do not have an estimate of HIST 12 months ago, we set the quantity to 1 (Hollstein \& Prokopczuk, 2016).

${ }^{11}$ Strictly speaking, the Wilcoxon signed rank test incorporates the joint null hypothesis of zero median in the loss differentials as well as a symmetric distribution. We stick to this test instead of an alternative only testing on zero median, like the simple sign test, since the Wilcoxon signed rank test turns out to be more powerful in many applications (Conover, 1999).
} 
beta based on daily data (Panel $\mathrm{C}$ of Table 6). In the former case, we find that $\mathrm{HF}_{30}$ still yields a substantially lower RMSE than HIST. In this setup, however, the highfrequency estimator with 1 lag $\left(\mathrm{HF}_{30}^{(1)}\right)$ yields the overall lowest RMSE. When realized beta is estimated with daily data, we obtain the same pattern, the average RMSE of $\mathrm{HF}_{30}$ is lower than that of HIST. Due to the increased noise introduced by measurement error in the daily realized beta, however, only few of the differences in this panel are statistically significant. Nevertheless, we believe that the results of this analysis are meaningful in that if $\mathrm{HF}_{30}$ was systematically biased, it would also be systematically biased in comparison to the realized beta based on daily data used in this analysis. Thus, in this case it would be very unlikely that we observe that $\mathrm{HF}_{30}$ yields a lower average RMSE than HIST.

We find that in general the average RMSEs increase for all estimators when moving from 30-minute realized betas to those with lag-adjustments or those based on daily data, while the general ranking among the estimators largely prevails. The higher RMSEs of Panels $\mathrm{B}$ and $\mathrm{C}$ of Table 6 indicate that the corresponding realized betas are contaminated by higher measurement error. Therefore, in the following we will focus the main discussion on the 30-minute realized beta, while examining the robustness to this choice for all the main tests.

To shed further light on the predictability of the 5 portfolios, Figure 1 shows scatterplots of the predicted and realized betas for each estimation approach. We find that HIST and $\operatorname{HIST}^{(1)}$ spread relatively widely from the 45-degree line. Especially for portfolios with high and low predicted betas, the approaches produce large forecast errors. For $\mathrm{HF}_{30}$ and $\mathrm{HF}_{30}^{(1)}$, in contrast, the dots are much closer to the 45-degree line. The predictions and realizations match very well, independently of the magnitude of the predicted betas.

However, HIST might not be the optimal alternative estimator for beta. Taken together, the studies of Buss \& Vilkov (2012) and Hollstein \& Prokopczuk (2016) show that 
the BV estimator outperforms all other approaches based on daily data both statistically and economically. Therefore, we also add this estimator as a second benchmark. At each point in time, the BV estimator is only available for the stocks that are currently in the S\&P 500. Thus, to be able to compare the results and assess their statistical significance, we repeat the previous analysis only including the constituents of the S\&P 500 at each point in time.

We present these results in Table 7. Using a high-frequency realized beta in Panel A, we find that $\mathrm{HF}_{30}$ clearly outperforms all other models, including $\mathrm{BV}$ and $\mathrm{BV}_{30}$. When using high-frequency realized beta with lag-adjustment in Panel B, we find once more that $\mathrm{HF}_{30}^{(1)}$ yields the lowest average RMSE. However, that of $\mathrm{HF}_{30}$ and $\mathrm{BV}$ is only marginally and not statistically significantly higher. Using realized beta based on daily data (Panel C), $\mathrm{HF}_{30}$ again yields a lower average RMSE than HIST. Interestingly, for the S\&P 500 stocks, the outperformance of $\mathrm{HF}_{30}$ over HIST is even more pronounced, indicating that high-frequency data are particularly useful for the large stocks which are traded most frequently among those in our total sample.

Comparing $\mathrm{HF}_{30}$ and $\mathrm{BV}$, we find that $\mathrm{HF}_{30}$ performs at least as well as BV. Finally, another interesting observation relates to the comparison of $\mathrm{BV}$ and $\mathrm{BV}_{30}$. We find that BV yields lower average RMSEs than $\mathrm{BV}_{30}$ for every specification. Thus, the use of highfrequency data does not appear to be beneficial for this estimator. This finding is likely caused by the need to estimate the full correlation matrix and not only one bivariate correlation as for $\mathrm{HF}_{30}$, where the issue of non-synchronous trading is severely amplified.

We have also generated scatterplots, similar to that in Figure 1 for $\mathrm{BV}$ and $\mathrm{BV}_{30}$ (not shown). We find that both approaches tend to underestimate the betas of low-beta portfolios and overestimate those of high-beta portfolios. For beta estimates around 1, the approach works reasonably well. The scatterplots for HIST and BV are comparable 
to those in Buss \& Vilkov (2012).

\section{Alternative Frequencies}

In Table 8, we present the results for high-frequency beta estimators based on alternative sampling frequencies of 5 minutes, 75 minutes, and 130 minutes, both with and without lag adjustment. All results are very similar as before for the 30-minute frequency. The high-frequency estimators for coarser frequencies outperform HIST throughout. For our entire sample, the 5-minute frequency appears to be a little too high. Especially for realized beta with lag adjustment or daily data, the 5-minute frequency leads to high average RMSEs.

\section{Information Content}

An alternative way to evaluate the performance of ex-ante estimates is to use Mincer \& Zarnowitz (1969) regressions. We regress the 1-month (ex-post) realized beta on the different predictions for beta:

$$
\beta_{t, T}^{\mathrm{R}}=a+b \beta_{t}+\epsilon_{T},
$$

where $\beta_{t}$ denotes one beta estimate in univariate regressions or a vector of several beta estimates in encompassing regressions. $\beta_{t, T}^{R}$ is as previously defined.

The regression model in Equation (8) is designed to test for the informational efficiency and unbiasedness of different estimators. We stick to level Mincer-Zarnowitz regressions instead of logarithmically transforming our variables since beta is theoretically unbounded and can also take negative values. Hansen \& Lunde (2006) show that level MincerZarnowitz regressions are robust to (mean zero) errors in the evaluation proxy. 
We test for unbiasedness in univariate regressions using a Wald test, which imposes the joint hypothesis that $a=0$ and $b=1$. If the model is unbiased, i.e., it adequately describes the data, we will not be able to reject this hypothesis. We test for informational efficiency in encompassing regressions by restricting the slope parameters of alternative estimators to 0 . This test determines whether an estimator contains information beyond that of a baseline model. If an estimator adds value, its encompassing slope estimate must be significant (and positive) and the explanatory power must rise compared to the restricted model. We perform a Wald test to assess whether an estimator fully subsumes all the information contained in another estimator. To do this, we test the null hypothesis that adding an estimator does not increase the explanatory power compared to the (restricted) univariate models.

Table 9 presents the results of the Mincer-Zarnowitz regressions. In Panel A, we present the univariate regressions. Note that for univariate regressions the $t$-statistics of the slope coefficients, as part of the unbiasedness hypothesis, test the hypothesis of $b=1$ and not, as is usually done, $b=0$. Since we expect a positive relationship between the expected and realized beta, in multivariate regressions we consider a one-sided test of $b=0$ against $b>0$. All $t$-statistics and Wald tests use robust Newey \& West (1987) standard errors with 4 lags.

If an approach yields noisy estimates of beta, the slope coefficient of the MincerZarnowitz regression will be biased downwards. As a result, the intercept estimate is biased upwards. Comparing the average slope coefficients of HIST and $\mathrm{HF}_{30}$, we find them to be substantially closer to 1 (0.77 vs. 0.88$)$ for the high-frequency estimator. The intercept is substantially smaller for $\mathrm{HF}_{30}$ while the average adjusted $R^{2}$ increases from 0.64 to 0.73 when moving from HIST to $\mathrm{HF}_{30}$. These results are consistent with the notion that using high-frequency data reduces the measurement error in historical beta. 
For HIST, we can reject the unbiasedness hypothesis for each portfolio, while for $\mathrm{HF}_{30}$, we cannot reject this hypothesis for 3 out of 5 portfolios. For the approaches that include lag-adjustments, we find qualitatively similar results with somewhat smaller adjusted $R^{2}$ s.

We next examine the results of the encompassing regressions in Panel B of Table 9. In a joint regression with HIST and $\mathrm{HF}_{30}$, we find that the slope coefficient on HIST is -0.01 on average while that on $\mathrm{HF}_{30}$ is 0.88 . Thus, $\mathrm{HF}_{30}$ appears to subsume most of the information contained in HIST.

\section{E Cross-Sectional Predictability}

Up to this point, we focus on the time-series dimension of prediction errors. However, a good approach for estimating beta should do well both in the time-series and in the cross-section, i.e., the stocks should be properly ranked and the expected cross-sectional differences in beta should line up well with the realized cross-sectional differences. This insight motivates two additional tests. First, we examine the average of the cross-sectional Spearman rank correlations of the estimates of each approach with the realizations of beta. For an approach to work well, the rank correlation should be close to 1. Secondly, to capture the magnitude of cross-sectional predictability, we use Fama \& MacBeth (1973) cross-sectional regressions of realized beta on the estimates of each approach. That is, each month, we fit the following cross-sectional regression model:

$$
\beta_{j, t, T}^{\mathrm{R}}=a_{T}+b_{T} \beta_{j, t}+\epsilon_{j, t, T},
$$

where $a_{T}$ and $b_{T}$ denote the time $T$ regression intercept and slope, respectively. All other variables are as previously defined. To estimate Equation (9), we follow the IV-GMM approach of Kim \& Skoulakis (2016). A good model should have an intercept close to 0, 
a slope coefficient close to 1 , and a high $R^{2}$.

We present the results in Table 10. In Panel A, we examine the rank correlations. We observe that high-frequency data are valuable for estimating beta in terms of ranking the stocks. The average rank correlation of $\mathrm{HF}_{30}$ is 0.80 , whereas for HIST the rank correlation

amounts to only 0.69. For $\mathrm{HF}_{30}^{(1)}$ and $\mathrm{HIST}^{(1)}$ the rank coefficients are somewhat lower than those for $\mathrm{HF}_{30}$ and HIST, respectively. For all approaches, the average $p$-value is close to zero. Hence, all approaches appear to be able to significantly predict the cross-sectional ranks of beta. Overall, the highest average rank correlation is obtained for $\mathrm{HF}_{30}$.

Panel B of Table 10 shows the results of cross-sectional regressions. We find that using high-frequency data improves the cross-sectional predictability. Looking at the parameter estimates for $\mathrm{HF}_{30}$, we can see that the slope coefficient is of a similar magnitude as that of HIST. However, $\mathrm{HF}_{30}$ clearly yields the highest cross-sectional $R^{2}$, with 0.66 , which indicates its superior cross-sectional predictability compared to all other approaches.

\section{F Mean Absolute Error}

Lastly, we test the robustness of our results to an alternative loss function, i.e., the MAE:

$$
\mathrm{MAE}=\frac{1}{n} \sum_{t=1}^{n}\left|\beta_{t, T}^{R}-\beta_{t}\right|
$$

where all variables are as previously defined. The results for 5 portfolios are presented in Table 11. These are qualitatively similar to those using the RMSE criterion. Overall, $\mathrm{HF}_{30}$ also yields the lowest average MAE. 


\section{Conclusion}

This paper tests the conditional CAPM with betas based on daily and high-frequency data. While with daily data, the model cannot explain the size anomaly and 3 of the 6 component returns of the 3 main anomalies, the conditional CAPM can explain the size, value, and momentum anomalies, as well as 5 out of 6 of the component portfolio returns, when using high-frequency data.

We find that the superior economic value of high-frequency betas is associated with a superior predictability for future realized beta. Betas estimated from high-frequency data are significantly more accurate than those estimated from daily return data. We find that betas estimated from high-frequency data also outperform those based on daily data in Mincer-Zarnowitz regressions and have a superior cross-sectional predictability. 


\section{Technical Appendix: Model-Free Option-Implied Volatil- ity}

The hybrid beta estimation approach is based on option-implied moments. Therefore, we build on the work of Bakshi et al. (2003) and compute the model-free option-implied volatility. Similar to Chang et al. (2012), we first compute ex-dividend stock prices. Next, we interpolate implied volatilities on a grid of 1,000 moneyness levels $(\mathrm{K} / \mathrm{S}$, striketo-spot), equally spaced between $0.3 \%$ and $300 \%$, for any given stock and trading day. We extrapolate implied volatilities outside the range of available strike prices using the value for the smallest, respectively largest, available moneyness level (as in Jiang \& Tian, 2005 and Chang et al., 2012). We use the interpolated volatilities to compute Black \& Scholes (1973) option prices for calls, $C(\cdot)$, if $\mathrm{K} / \mathrm{S}>1$ and puts, $P(\cdot)$, if $\mathrm{K} / \mathrm{S}<1$. We use these prices to obtain the prices of the volatility (QUAD), the CUBIC, and the quartic (QUART) contract (Jiang \& Tian, 2005):

$$
\begin{aligned}
\text { QUAD }= & \int_{S}^{\infty} \frac{2\left(1-\ln \left[\frac{K}{S}\right]\right)}{K^{2}} C(T-t, K) d K \\
& +\int_{0}^{S} \frac{2\left(1+\ln \left[\frac{S}{K}\right]\right)}{K^{2}} P(T-t, K) d K, \\
\text { CUBIC }= & \int_{S}^{\infty} \frac{6 \ln \left[\frac{K}{S}\right]-3\left(\ln \left[\frac{K}{S}\right]\right)^{2}}{K^{2}} C(T-t, K) d K \\
& +\int_{0}^{S} \frac{6 \ln \left[\frac{S}{K}\right]+3\left(\ln \left[\frac{S}{K}\right]\right)^{2}}{K^{2}} P(T-t, K) d K, \\
\text { QUART }= & \int_{S}^{\infty} \frac{12\left(\ln \left[\frac{K}{S}\right]\right)^{2}-4\left(\ln \left[\frac{K}{S}\right]\right)^{3}}{K^{2}} C(T-t, K) d K \\
& +\int_{0}^{S} \frac{12\left(\ln \left[\frac{S}{K}\right]\right)^{2}+4\left(\ln \left[\frac{S}{K}\right]\right)^{3}}{K^{2}} P(T-t, K) d K .
\end{aligned}
$$

We approximate the integrals using a trapezoidal rule (Dennis \& Mayhew, 2002). The 
option-implied moments can be computed as:

$$
\begin{aligned}
\mu_{t, T}^{\mathbb{Q}} & =e^{r_{f, t}(T-t)}-1-\frac{e^{r_{f, t}(T-t)}}{2} \mathrm{QUAD}-\frac{e^{r_{f, t}(T-t)}}{6} \mathrm{CUBIC}-\frac{e^{r_{f, t}(T-t)}}{24} \mathrm{QUART}, \text { (A4) } \\
\left(\sigma_{t, T}^{\mathbb{Q}}\right)^{2} & =e^{r_{f, t}(T-t)} \mathrm{QUAD}-\left(\mu^{\mathbb{Q}}\right)^{2},
\end{aligned}
$$

where $r_{f, t}$ denotes the risk-free rate and $T-t$ the time to maturity of the contract. $\left(\sigma^{\mathbb{Q}}\right)^{2}$ is the option-implied variance. 


\section{References}

Amaya, D., Christoffersen, P., Jacobs, K., \& Vasquez, A. (2015). Does realized skewness predict the cross-section of equity returns? Journal of Financial Economics, 118(1), $135-167$.

Amihud, Y. (2002). Illiquidity and stock returns: Cross-section and time-series effects. Journal of Financial Markets, 5(1), 31-56.

Andersen, T. G., \& Bollerslev, T. (1998). Answering the skeptics: Yes, standard volatility models do provide accurate forecasts. International Economic Review, 39(4), 885-905.

Andersen, T. G., Bollerslev, T., Diebold, F. X., \& Wu, J. G. (2005a). A framework for exploring the macroeconomic determinants of systematic risk. American Economic Review: Papers and Proceedings, 95(2), 398-404.

Andersen, T. G., Bollerslev, T., Diebold, F. X., \& Wu, J. G. (2006). Realized beta: Persistence and predictability. In T. B. Fomby, \& D. Terrell (Eds.) Advances in Econometrics: Econometric Analysis of Economic and Financial Time Series, (pp. 1-40). New York: Elsevier.

Andersen, T. G., Bollerslev, T., \& Meddahi, N. (2005b). Correcting the errors: Volatility forecast evaluation using high-frequency data and realized volatilities. Econometrica, $73(1), 279-296$.

Bakshi, G., Kapadia, N., \& Madan, D. (2003). Stock return characteristics, skew laws, and the differential pricing of individual equity options. Review of Financial Studies, $16(1), 101-143$.

Banz, R. W. (1981). The relationship between return and market value of common stocks. Journal of Financial Economics, 9(1), 3-18.

Barndorff-Nielsen, O. E., Hansen, P. R., Lunde, A., \& Shephard, N. (2009). Realized kernels in practice: Trades and quotes. Econometrics Journal, 12(3), 1-32.

Barndorff-Nielsen, O. E., \& Shephard, N. (2004). Econometric analysis of realized covariation: High frequency based covariance, regression, and correlation in financial economics. Econometrica, $72(3)$, 885-925.

Baule, R., Korn, O., \& Saßning, S. (2016). Which beta is best? On the information content of option-implied betas. European Financial Management, 22(3), 450-483.

Black, F., Jensen, M., \& Scholes, M. (1972). The capital asset pricing model: Some empirical tests. In M. Jensen (Ed.) Studies in the Theory of Capital Markets, (pp. 79-121). New York: Praeger.

Black, F., \& Scholes, M. (1973). The pricing of options and corporate liabilities. Journal of Political Economy, 81(3), 637-654. 
Boguth, O., Carlson, M., Fisher, A., \& Simutin, M. (2011). Conditional risk and performance evaluation: Volatility timing, overconditioning, and new estimates of momentum alphas. Journal of Financial Economics, 102(2), 363-389.

Bollerslev, T., Li, S. Z., \& Todorov, V. (2016). Roughing up beta: Continuous versus discontinuous betas and the cross-section of expected stock returns. Journal of Financial Economics, 120(3), 464-490.

Bollerslev, T., \& Todorov, V. (2010). Jumps and betas: A new framework for disentangling and estimating systematic risks. Journal of Econometrics, 157(2), 220-235.

Bollerslev, T., \& Zhang, B. Y. (2003). Measuring and modeling systematic risk in factor pricing models using high-frequency data. Journal of Empirical Finance, $10(5), 533-$ 558.

Buss, A., \& Vilkov, G. (2012). Measuring equity risk with option-implied correlations. Review of Financial Studies, 25(10), 3113-3140.

Cenesizoglu, T., Liu, Q., Reeves, J. J., \& Wu, H. (2016). Monthly beta forecasting with low-, medium-and high-frequency stock returns. Journal of Forecasting, 35 (6), 528-541.

Chang, B.-Y., Christoffersen, P., Jacobs, K., \& Vainberg, G. (2012). Option-implied measures of equity risk. Review of Finance, 16(2), 385-428.

Cohen, R. B., Gompers, P. A., \& Vuolteenaho, T. (2002). Who underreacts to cashflow news? Evidence from trading between individuals and institutions. Journal of Financial Economics, 66(2-3), 409-462.

Conover, W. (1999). Practical Nonparametric Statistics. New York: Wiley, 3 ed.

Dennis, P., \& Mayhew, S. (2002). Risk-neutral skewness: Evidence from stock options. Journal of Financial and Quantitative Analysis, 37(3), 471-493.

Dimson, E. (1979). Risk measurement when shares are subject to infrequent trading. Journal of Financial Economics, 7(2), 197-226.

Epps, T. W. (1979). Comovements in stock prices in the very short run. Journal of the American Statistical Association, 74 (366a), 291-298.

Fama, E. F., \& French, K. R. (1992). The cross-section of expected stock returns. Journal of Finance, $47(2), 427-465$.

Fama, E. F., \& MacBeth, J. D. (1973). Risk, return, and equilibrium: Empirical tests. Journal of Political Economy, 81(3), 607-636.

Gilbert, T., Hrdlicka, C., Kalodimos, J., \& Siegel, S. (2014). Daily data is bad for beta: Opacity and frequency-dependent betas. Review of Asset Pricing Studies, 4 (1), 78-117. 
Gorodnichenko, Y., \& Weber, M. (2016). Are sticky prices costly? Evidence from the stock market. American Economic Review, 106(1), 165-199.

Goyal, A., \& Jegadeesh, N. (2018). Cross-sectional and time-series tests of return predictability: What is the difference? Review of Financial Studies, 31 (5), 1784-1824.

Grundy, B. D., \& Martin, J. S. M. (2001). Understanding the nature of the risks and the source of the rewards to momentum investing. Review of Financial Studies, 14(1), 29-78.

Hansen, L. P., \& Richard, S. F. (1987). The role of conditioning information in deducing testable restrictions implied by dynamic asset pricing models. Econometrica, 55(3), 587-613.

Hansen, P. R., \& Lunde, A. (2006). Consistent ranking of volatility models. Journal of Econometrics, 131(1), 97-121.

Harvey, D., Leybourne, S., \& Newbold, P. (1997). Testing the equality of prediction mean squared errors. International Journal of Forecasting, 13(2), 281-291.

Hollstein, F., \& Prokopczuk, M. (2016). Estimating beta. Journal of Financial and Quantitative Analysis, 51(4), 1437-1466.

Hou, K., \& Loh, R. K. (2016). Have we solved the idiosyncratic volatility puzzle? Journal of Financial Economics, 121(1), 167-194.

Hou, K., Xue, C., \& Zhang, L. (2015). Digesting anomalies: An investment approach. Review of Financial Studies, 28(3), 650-705.

Hou, K., Xue, C., \& Zhang, L. (2018). Replicating anomalies. Review of Financial Studies, forthcoming.

Jagannathan, R., \& Wang, Z. (1996). The conditional CAPM and the cross-section of expected returns. Journal of Finance, 51(1), 3-53.

Jegadeesh, N., \& Titman, S. (1993). Returns to buying winners and selling losers: Implications for stock market efficiency. Journal of Finance, 48(1), 65-91.

Jiang, G. J., \& Tian, Y. S. (2005). The model-free implied volatility and its information content. Review of Financial Studies, 18(4), 1305-1342.

Kim, S., \& Skoulakis, G. (2016). Ex-post risk premia tests using individual stocks: The IV-GMM solution to the EIV problem. Georgia Tech Working Paper.

Lettau, M., \& Ludvigson, S. (2001). Resurrecting the (C) CAPM: A cross-sectional test when risk premia are time-varying. Journal of Political Economy, 109(6), 1238-1287.

Lewellen, J., \& Nagel, S. (2006). The conditional CAPM does not explain asset-pricing anomalies. Journal of Financial Economics, 82(2), 289-314. 
Lintner, J. (1965). The valuation of risk assets and the selection of risky investments in stock portfolios and capital budgets. Review of Economics and Statistics, 47(1), 13-37.

Lustig, H. N., \& Van Nieuwerburgh, S. G. (2005). Housing collateral, consumption insurance, and risk premia: An empirical perspective. Journal of Finance, 60 (3), 1167-1219.

Mincer, J. A., \& Zarnowitz, V. (1969). The evaluation of economic forecasts. In J. Mincer (Ed.) Economic Forecasts and Expectations: Analysis of Forecasting Behavior and Performance, (pp. 1-46). Cambridge, MA: Elsevier.

Mossin, J. (1966). Equilibrium in a capital asset market. Econometrica, 34(4), 768-783.

Newey, W. K., \& West, K. D. (1987). A simple, positive semi-definite, heteroskedasticity and autocorrelation consistent covariance matrix. Econometrica, 55(3), 703-708.

Patton, A. J. (2011). Volatility forecast comparison using imperfect volatility proxies. Journal of Econometrics, 160(1), 246-256.

Patton, A. J., \& Verardo, M. (2012). Does beta move with news? Firm-specific information flows and learning about profitability. Review of Financial Studies, 25(9), 2789-2839.

Santos, T., \& Veronesi, P. (2005). Labor income and predictable stock returns. Review of Financial Studies, 19(1), 1-44.

Scholes, M., \& Williams, J. (1977). Estimating betas from nonsynchronous data. Journal of Financial Economics, 5(3), 309-327.

Sharpe, W. F. (1964). Capital asset prices: A theory of market equilibrium under conditions of risk. Journal of Finance, $19(3), 425-442$.

Zhang, X. (2006). Information uncertainty and stock returns. Journal of Finance, 61(1), 105-137. 


\section{Figure 1: Predicted Beta vs. Realized Beta - Scatterplots}

This figure shows the scatterplots of predicted and realized beta. Each month, we sort the stocks into 5 portfolios according to their estimate for HIST 12 months before. For each of the portfolios, we compute the value-weighted average predicted beta as well as the realized beta over the next month, using 30-minute returns. We plot the realized quintile betas vs. the predicted portfolio betas for each quintile, month, and estimation methodology. Each figure includes a $45^{\circ}$ line, a fitted regression line, as well as the adjusted $\mathrm{R}^{2}$ of the regression.
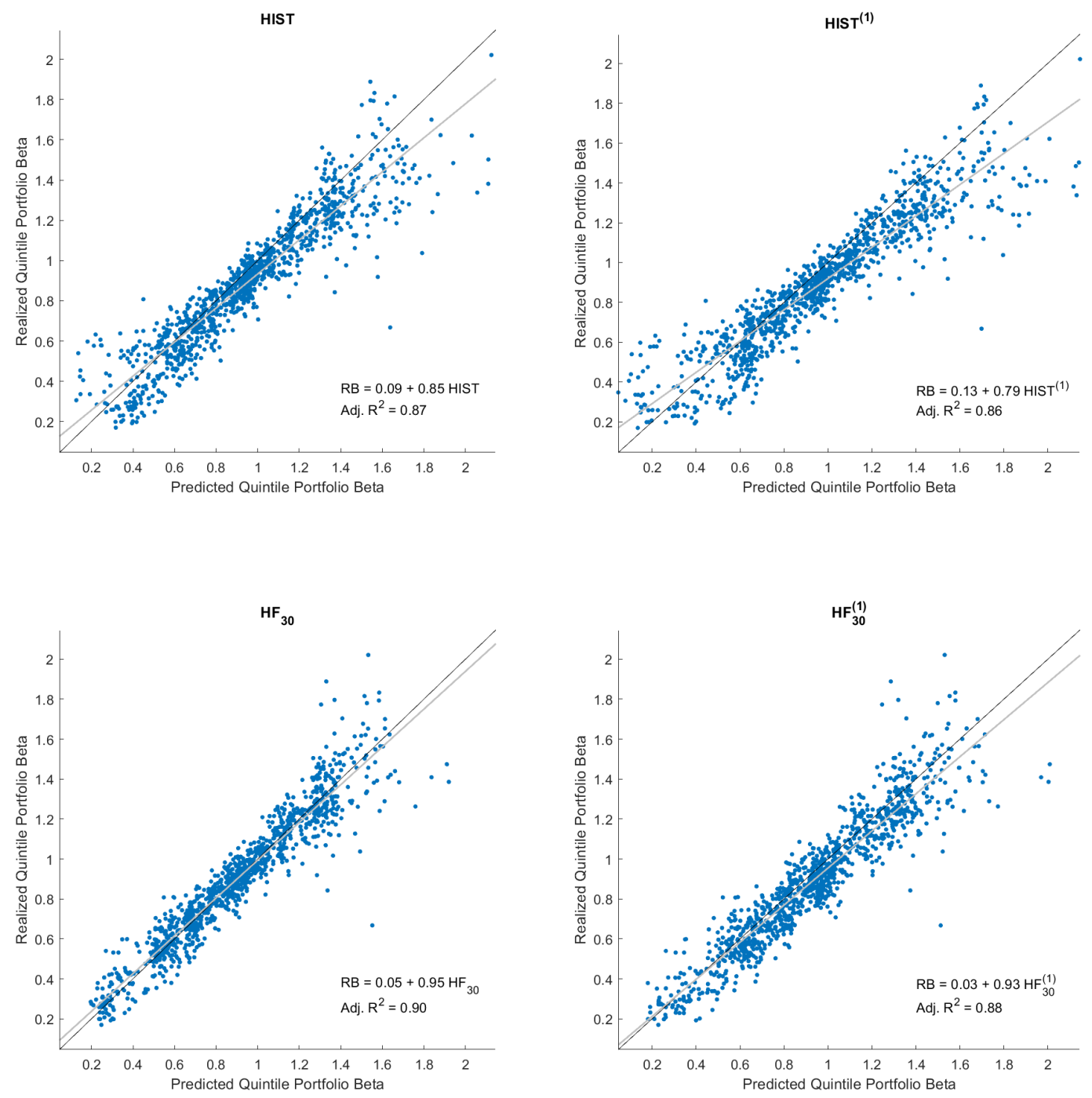


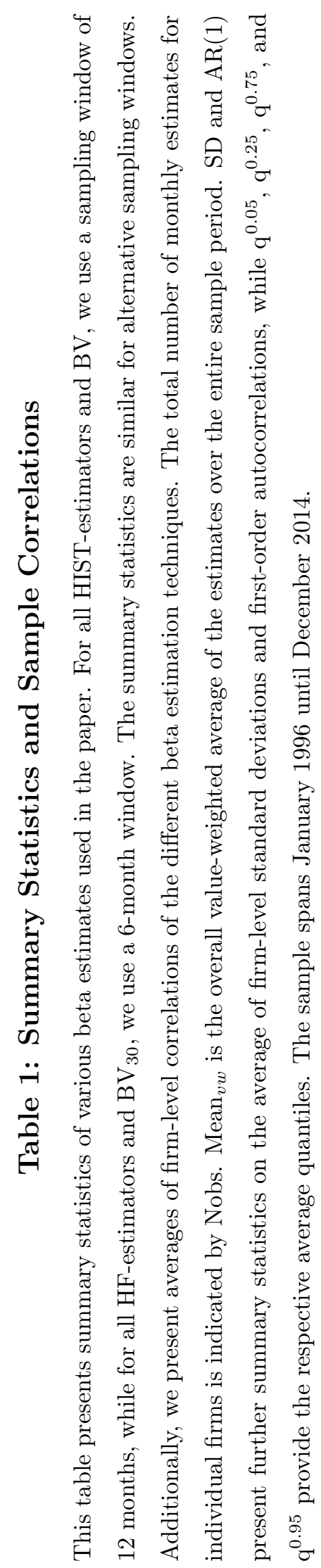

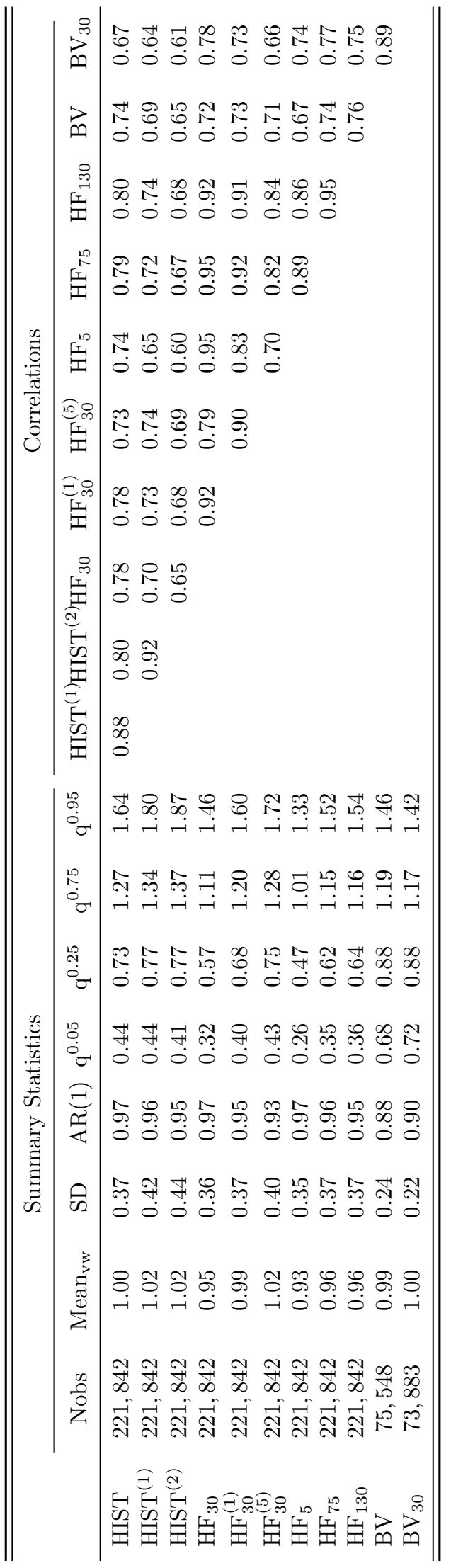



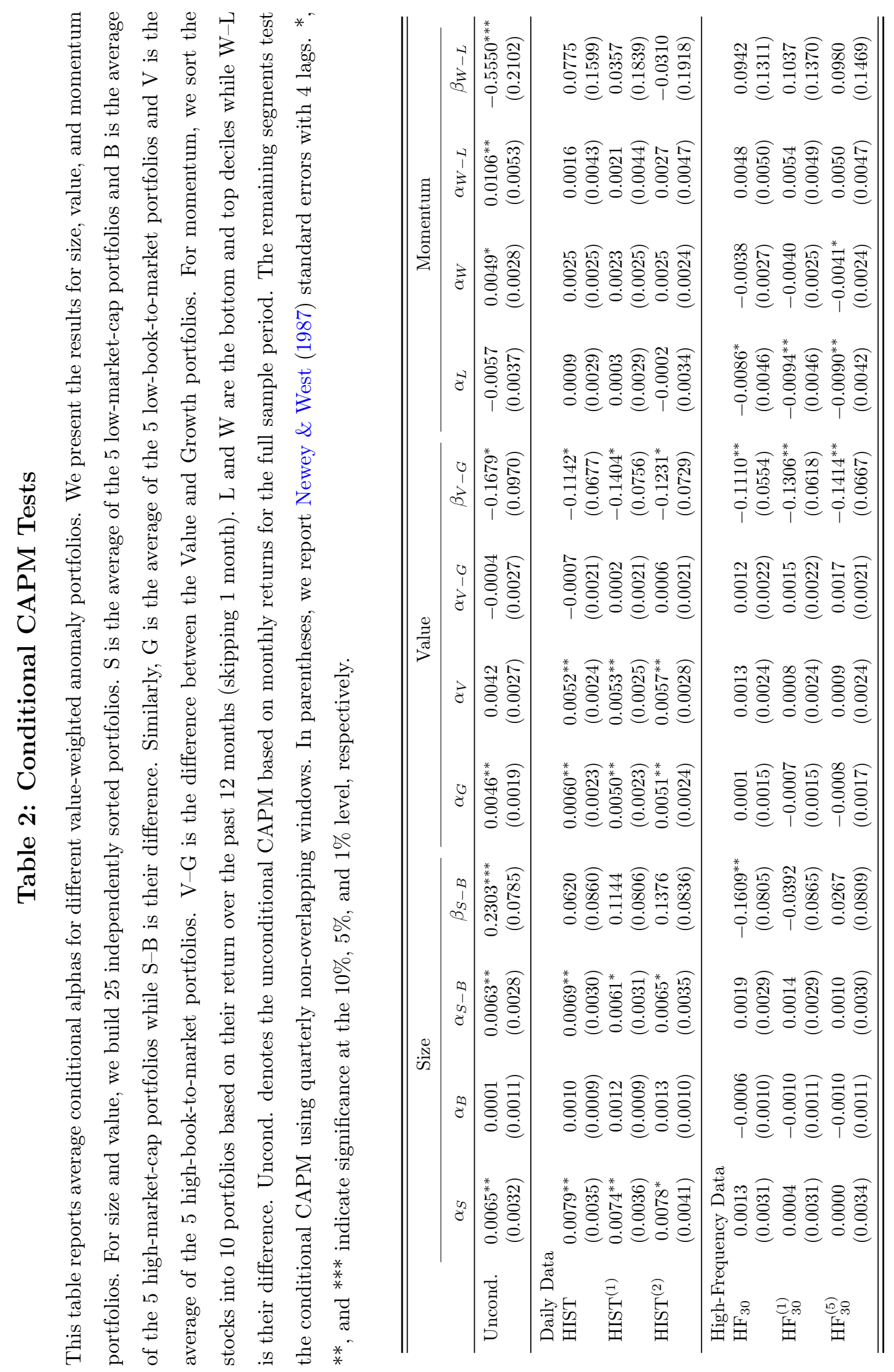


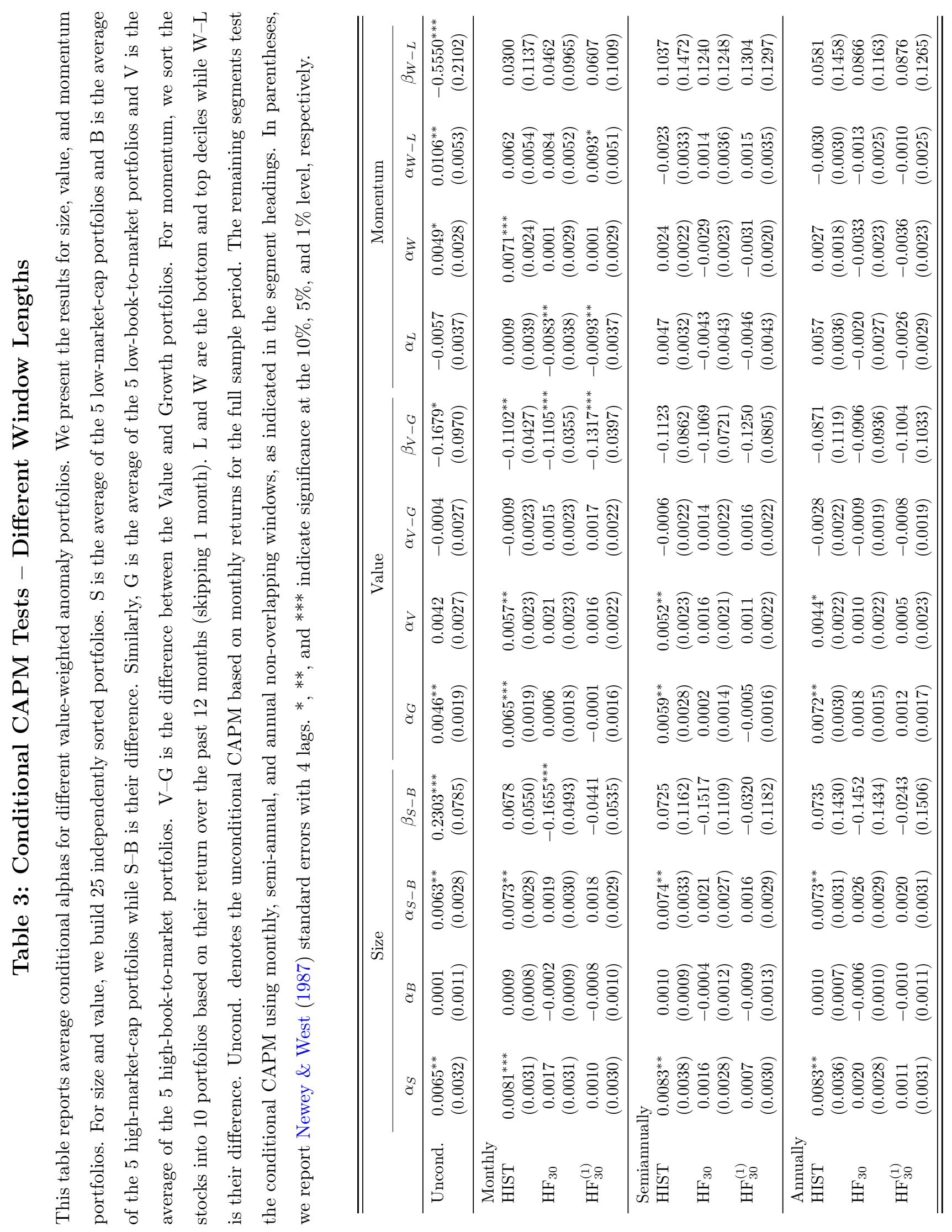




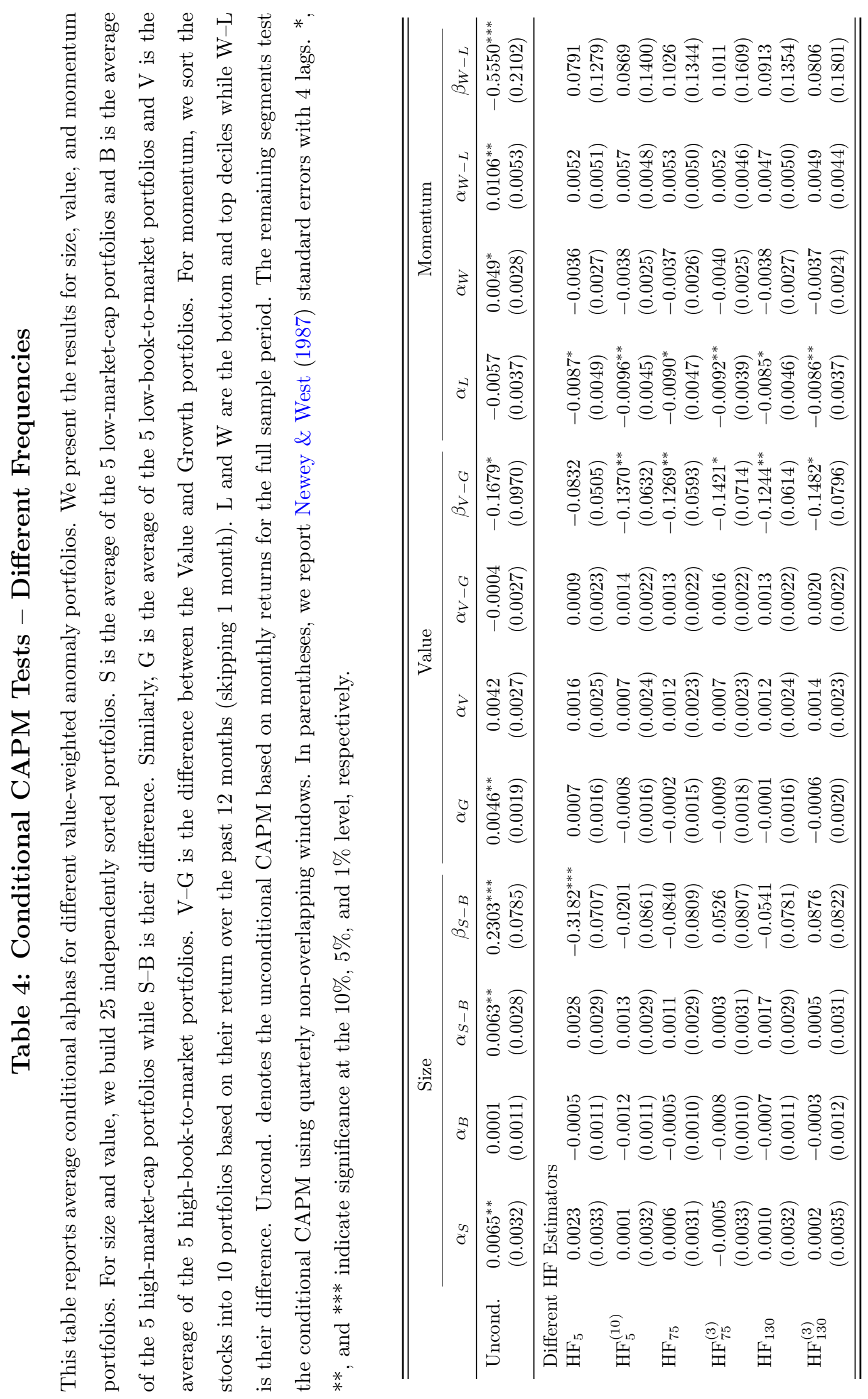




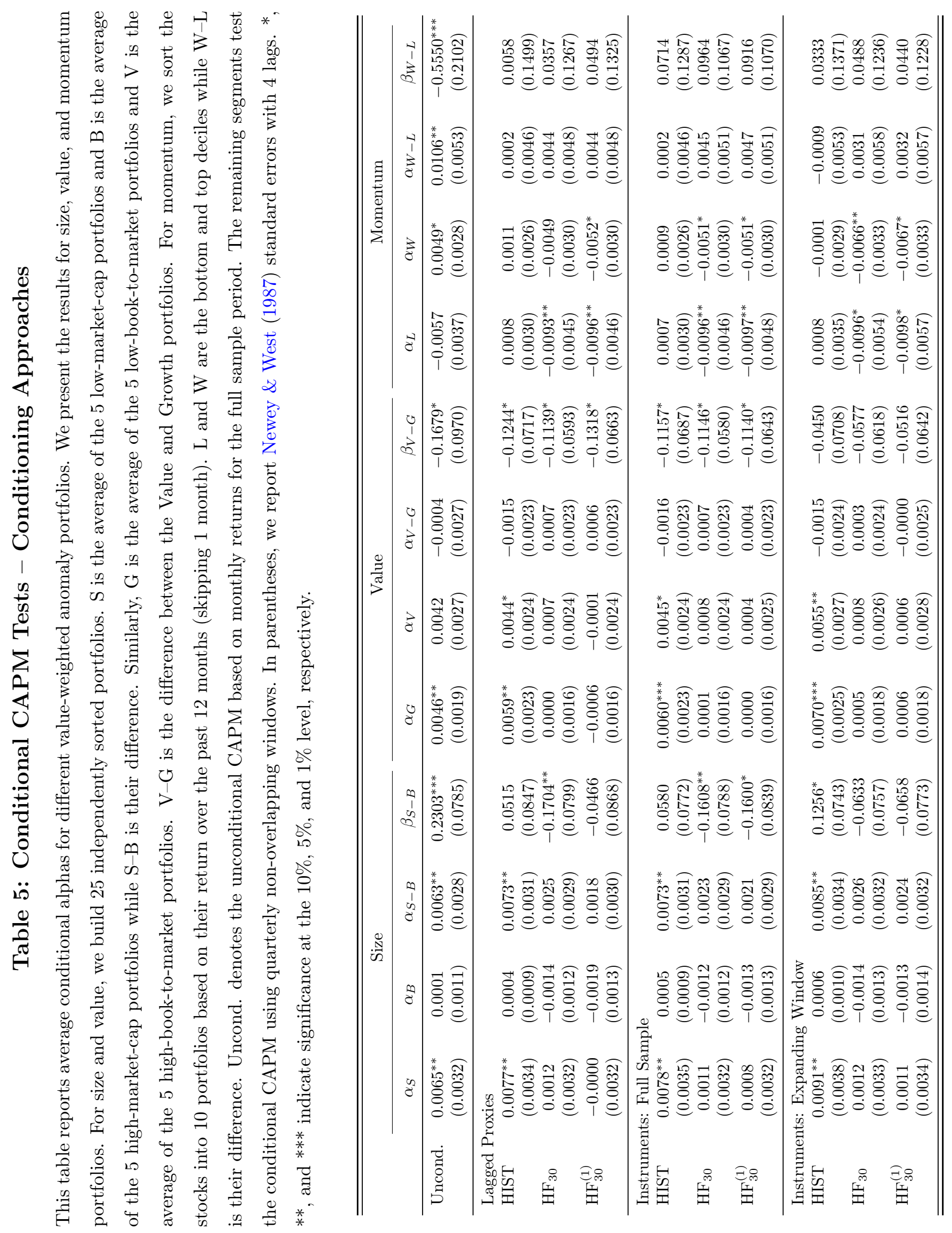




\section{Table 6: Prediction Errors}

This table presents the out-of-sample prediction errors of different approaches. Each month, we sort the stocks into 5 portfolios according to their estimate for HIST 12 months before. We obtain valueweighted average betas for each portfolio and approach and measure the realized beta of each portfolio using 5-minute returns over the subsequent month. The first row reports the average RMSE across all portfolios. The lowest average error is indicated by italic font. The remainder of the table reports the differences in prediction errors. The upper triangular matrices report the differences in RMSE, averaged over all portfolios. Similarly, the lower triangular matrices report the average differences in RMedSE. We report the error loss differential between the model [name in row] and the model [name in column]. The absolute values of the numbers in parentheses indicate the share of portfolios for which the difference is significant at 5\% (e.g., 0.4 indicates that the difference is significant for $40 \%$ of the portfolios). Figures printed in bold indicate that the differences are significant for all portfolios. We test significance with the modified Diebold-Mariano and the Wilcoxon signed rank tests for the upper and lower triangular matrices, respectively. The sign of the number in parentheses indicates the direction of the significant differences.

\section{Panel A. Realized Beta}

\begin{tabular}{lcccc}
\hline \hline & HIST & $\mathrm{HIST}^{(1)}$ & $\mathrm{HF}_{30}$ & $\mathrm{HF}_{30}^{(1)}$ \\
\hline Avg. RMSE & 0.1352 & 0.1542 & 0.0949 & 0.1180 \\
\hline \hline HIST & & -0.0190 & 0.0403 & 0.0172 \\
& & $\mathbf{( - 1 . 0 0 )}$ & $\mathbf{( 1 . 0 0 )}$ & $(0.40)$ \\
$\mathrm{HIST}^{(1)}$ & 0.0118 & & 0.0593 & 0.0362 \\
& $\mathbf{( 1 . 0 0 )}$ & & $\mathbf{( 1 . 0 0 )}$ & $\mathbf{( 1 . 0 0 )}$ \\
$\mathrm{HF}_{30}$ & -0.0277 & -0.0395 & & -0.0231 \\
& $\mathbf{( - 1 . 0 0 )}$ & $\mathbf{( - 1 . 0 0 )}$ & & $\mathbf{( - 1 . 0 0 )}$ \\
$\mathrm{HF}_{30}^{(1)}$ & -0.0064 & -0.0181 & 0.0214 & \\
& $(-0.40)$ & $(-0.80)$ & $\mathbf{( 1 . 0 0 )}$ & \\
\hline \hline
\end{tabular}


Table 6: Prediction Errors (continued)

Panel B. Realized Beta With Lag-Adjustment

\begin{tabular}{lcccc}
\hline \hline & HIST & HIST $^{(1)}$ & $\mathrm{HF}_{30}$ & $\mathrm{HF}_{30}^{(1)}$ \\
\hline Avg. RMSE & 0.1491 & 0.1587 & 0.1344 & 0.1276 \\
\hline \hline HIST & & -0.0095 & 0.0147 & 0.0216 \\
& & $(-0.40)$ & $(0.20)$ & $(0.80)$ \\
HIST $^{(1)}$ & 0.0060 & & 0.0242 & 0.0311 \\
& $(0.40)$ & & $(0.40)$ & $\mathbf{1 . 0 0 )}$ \\
$\mathrm{HF}_{30}$ & -0.0011 & -0.0070 & & 0.0069 \\
& $(-0.20)$ & $(-0.20)$ & & $(0.60)$ \\
$\mathrm{HF}_{30}^{(1)}$ & -0.0111 & -0.0170 & -0.0100 & \\
& $(-0.60)$ & $(-0.80)$ & $(-0.60)$ & \\
\hline
\end{tabular}

Panel C. Daily Realized Beta

\begin{tabular}{lcccc}
\hline \hline & HIST & $\mathrm{HIST}^{(1)}$ & $\mathrm{HF}_{30}$ & $\mathrm{HF}_{30}^{(1)}$ \\
\hline Avg. RMSE & 0.1510 & 0.1561 & 0.1493 & 0.1466 \\
\hline \hline $\mathrm{HIST}$ & & -0.0052 & 0.0017 & 0.0044 \\
& & $(-0.20)$ & $(0.00)$ & $(0.00)$ \\
$\mathrm{HIST}^{(1)}$ & 0.0061 & & 0.0069 & 0.0096 \\
& $(0.20)$ & & $(0.20)$ & $(0.00)$ \\
$\mathrm{HF}_{30}$ & 0.0058 & -0.0003 & & 0.0027 \\
& $(0.40)$ & $(0.20)$ & & $(0.20)$ \\
$\mathrm{HF}_{30}^{(1)}$ & 0.0023 & -0.0039 & -0.0035 & \\
& $(0.00)$ & $(-0.20)$ & $(0.00)$ & \\
\hline \hline
\end{tabular}




\section{Table 7: Prediction Errors - S\&P 500 Stocks}

This table presents the out-of-sample prediction errors of different approaches. Each month, we sort the stocks in the S\&P 500 into 5 portfolios according to their estimate for HIST 12 months before. We obtain value-weighted average betas for each portfolio and approach and measure the realized beta of each portfolio using 5-minute returns over the subsequent month. The first row reports the average RMSE across all portfolios. The lowest average error is indicated by italic font. The remainder of the table reports the differences in prediction errors. The upper triangular matrices report the differences in RMSE, averaged over all portfolios. Similarly, the lower triangular matrices report the average differences in RMedSE. We report the error loss differential between the model [name in row] and the model [name in column]. The absolute values of the numbers in parentheses indicate the share of portfolios for which the difference is significant at $5 \%$ (e.g., 0.4 indicates that the difference is significant for $40 \%$ of the portfolios). Figures printed in bold indicate that the differences are significant for all portfolios. We test significance with the modified Diebold-Mariano and the Wilcoxon signed rank tests for the upper and lower triangular matrices, respectively. The sign of the number in parentheses indicates the direction of the significant differences.

\section{Panel A. Realized Beta}

\begin{tabular}{lcccccc}
\hline \hline & $\mathrm{HIST}$ & $\mathrm{HIST}^{(1)}$ & $\mathrm{HF}_{30}$ & $\mathrm{HF}_{30}^{(1)}$ & $\mathrm{BV}$ & $\mathrm{BV}_{30}$ \\
\hline Avg. RMSE & 0.1320 & 0.1421 & 0.0945 & 0.1163 & 0.1072 & 0.1145 \\
\hline \hline HIST & & -0.0101 & 0.0375 & 0.0157 & 0.0247 & 0.0174 \\
& & $(-0.60)$ & $\mathbf{( 1 . 0 0 )}$ & $(0.40)$ & $(0.60)$ & $(0.40)$ \\
$\mathrm{HIST}^{(1)}$ & 0.0107 & & 0.0476 & 0.0258 & 0.0349 & 0.0275 \\
& $(0.80)$ & & $\mathbf{( 1 . 0 0 )}$ & $(0.80)$ & $(0.60)$ & $(0.40)$ \\
$\mathrm{HF}_{30}$ & -0.0215 & -0.0322 & & -0.0218 & -0.0128 & -0.0201 \\
& $\mathbf{( - 1 . 0 0 )}$ & $\mathbf{( - 1 . 0 0 )}$ & & $\mathbf{( - 1 . 0 0 )}$ & $(-0.40)$ & $(-0.60)$ \\
$\mathrm{HF}_{30}^{(1)}$ & -0.0053 & -0.0161 & 0.0162 & & 0.0090 & 0.0017 \\
& $(-0.20)$ & $(-0.80)$ & $\mathbf{( 1 . 0 0 )}$ & & $(0.20)$ & $(0.00)$ \\
$\mathrm{BV}^{3}$ & -0.0114 & -0.0221 & 0.0101 & -0.0061 & & -0.0073 \\
$\mathrm{BV}_{30}$ & $(-0.40)$ & $(-0.80)$ & $(0.60)$ & $(-0.20)$ & & $(-0.60)$ \\
& -0.0061 & -0.0169 & 0.0154 & -0.0008 & 0.0053 & \\
\hline \hline
\end{tabular}


Table 7: Prediction Errors - S\&P 500 Stocks (continued)

Panel B. Realized Beta With Lag-Adjustment

\begin{tabular}{lcccccc}
\hline \hline & $\mathrm{HIST}$ & $\mathrm{HIST}^{(1)}$ & $\mathrm{HF}_{30}$ & $\mathrm{HF}_{30}^{(1)}$ & $\mathrm{BV}$ & $\mathrm{BV}_{30}$ \\
\hline Avg. RMSE & 0.1511 & 0.1571 & 0.1301 & 0.1292 & 0.1294 & 0.1364 \\
\hline \hline HIST & & -0.0060 & 0.0211 & 0.0220 & 0.0218 & 0.0148 \\
& & $(-0.40)$ & $(0.60)$ & $(0.60)$ & $(\mathbf{1 . 0 0 )}$ & $(0.60)$ \\
$\mathrm{HIST}^{(1)}$ & 0.0040 & & 0.0271 & 0.0280 & 0.0278 & 0.0208 \\
& $(0.40)$ & & $(0.80)$ & $\mathbf{( 1 . 0 0 )}$ & $(0.80)$ & $(0.60)$ \\
$\mathrm{HF}_{30}$ & -0.0089 & -0.0129 & & 0.0009 & 0.0007 & -0.0063 \\
& $(-0.60)$ & $(-0.40)$ & & $(0.00)$ & $(0.00)$ & $(0.00)$ \\
$\mathrm{HF}_{30}^{(1)}$ & -0.0116 & -0.0156 & -0.0027 & & -0.0002 & -0.0072 \\
& $(-0.20)$ & $(-0.80)$ & $(0.00)$ & & $(0.00)$ & $(-0.20)$ \\
$\mathrm{BV}^{3}$ & -0.0126 & -0.0166 & -0.0037 & -0.0010 & & -0.0070 \\
$\mathrm{BV}_{30}$ & $(-0.60)$ & $(-0.60)$ & $(-0.20)$ & $(0.20)$ & & $(-0.60)$ \\
& -0.0044 & -0.0085 & 0.0044 & 0.0071 & 0.0082 & \\
\hline \hline
\end{tabular}

Panel C. Daily Realized Beta

\begin{tabular}{lcccccc}
\hline \hline & $\mathrm{HIST}$ & $\mathrm{HIST}^{(1)}$ & $\mathrm{HF}_{30}$ & $\mathrm{HF}_{30}^{(1)}$ & $\mathrm{BV}$ & $\mathrm{BV}_{30}$ \\
\hline Avg. RMSE & 0.1550 & 0.1579 & 0.1431 & 0.1476 & 0.1416 & 0.1486 \\
\hline \hline HIST & & -0.0029 & 0.0119 & 0.0074 & 0.0135 & 0.0065 \\
& & $(-0.20)$ & $(0.40)$ & $(0.20)$ & $(0.60)$ & $(0.40)$ \\
$\mathrm{HIST}^{(1)}$ & 0.0000 & & 0.0148 & 0.0103 & 0.0164 & 0.0093 \\
& $(0.20)$ & & $(0.40)$ & $(0.20)$ & $(0.60)$ & $(0.60)$ \\
$\mathrm{HF}_{30}$ & -0.0038 & -0.0039 & & -0.0045 & 0.0015 & -0.0055 \\
& $(-0.40)$ & $(-0.40)$ & & $(0.00)$ & $(0.20)$ & $(0.00)$ \\
$\mathrm{HF}_{30}^{(1)}$ & -0.0027 & -0.0027 & 0.0011 & & 0.0061 & -0.0010 \\
& $(0.20)$ & $(0.00)$ & $(0.20)$ & & $(0.20)$ & $(0.00)$ \\
$\mathrm{BV}^{2}$ & -0.0116 & -0.0116 & -0.0077 & -0.0089 & & -0.0070 \\
& $(-0.40)$ & $(-0.40)$ & $(-0.40)$ & $(-0.60)$ & & $(-0.40)$ \\
$\mathrm{BV}_{30}$ & -0.0065 & -0.0065 & -0.0026 & -0.0038 & 0.0051 & \\
& $(0.00)$ & $(-0.40)$ & $(-0.20)$ & $(-0.20)$ & $(0.80)$ & \\
\hline \hline
\end{tabular}




\section{Table 8: Prediction Errors - Different Frequencies}

This table presents the out-of-sample prediction errors of different approaches. Each month, we sort the stocks into 5 portfolios according to their estimate for HIST 12 months before. We obtain valueweighted average betas for each portfolio and approach and measure the realized beta of each portfolio using 5-minute returns over the subsequent month. The first row reports the average RMSE across all portfolios. The lowest average error is indicated by italic font. The remainder of the table reports the differences in prediction errors. The upper triangular matrices report the differences in RMSE, averaged over all portfolios. Similarly, the lower triangular matrices report the average differences in RMedSE. We report the error loss differential between the model [name in row] and the model [name in column]. The absolute values of the numbers in parentheses indicate the share of portfolios for which the difference is significant at 5\% (e.g., 0.4 indicates that the difference is significant for $40 \%$ of the portfolios). Figures printed in bold indicate that the differences are significant for all portfolios. We test significance with the modified Diebold-Mariano and the Wilcoxon signed rank tests for the upper and lower triangular matrices, respectively. The sign of the number in parentheses indicates the direction of the significant differences.

Panel A. Realized Beta

\begin{tabular}{|c|c|c|c|c|c|c|c|c|c|c|}
\hline & HIST & $\mathrm{HIST}^{(1)}$ & $\mathrm{HF}_{30}$ & $\mathrm{HF}_{30}^{(1)}$ & $\mathrm{HF}_{5}$ & $\mathrm{HF}_{5}^{(10)}$ & $\mathrm{HF}_{75}$ & $\mathrm{HF}_{75}^{(1)}$ & $\mathrm{HF}_{130}$ & $\mathrm{HF}_{130}^{(1)}$ \\
\hline Avg. RMSE & 0.1353 & 0.1543 & 0.0949 & 0.1181 & 0.1012 & 0.1420 & 0.0980 & 0.1320 & 0.0995 & 0.1371 \\
\hline HIST & & $\begin{array}{l}-0.0190 \\
(-1.00)\end{array}$ & $\begin{array}{l}0.0404 \\
\mathbf{( 1 . 0 0 )}\end{array}$ & $\begin{array}{c}0.0172 \\
(0.40)\end{array}$ & $\begin{array}{l}0.0341 \\
\mathbf{( 1 . 0 0 )}\end{array}$ & $\begin{array}{l}-0.0067 \\
(-0.40)\end{array}$ & $\begin{array}{l}0.0373 \\
\mathbf{( 1 . 0 0 )}\end{array}$ & $\begin{array}{c}0.0033 \\
(0.00)\end{array}$ & $\begin{array}{l}0.0358 \\
\mathbf{( 1 . 0 0 )}\end{array}$ & $\begin{array}{l}-0.0018 \\
(-0.20)\end{array}$ \\
\hline $\mathrm{HIST}^{(1)}$ & $\begin{array}{l}0.0120 \\
\mathbf{( 1 . 0 0 )}\end{array}$ & & $\begin{array}{l}0.0594 \\
(\mathbf{1 . 0 0 )}\end{array}$ & $\begin{array}{l}0.0362 \\
(\mathbf{1 . 0 0 )}\end{array}$ & $\begin{array}{l}0.0531 \\
\mathbf{( 1 . 0 0 )}\end{array}$ & $\begin{array}{c}0.0122 \\
(0.20)\end{array}$ & $\begin{array}{l}0.0563 \\
(\mathbf{1 . 0 0 )}\end{array}$ & $\begin{array}{c}0.0223 \\
(0.60)\end{array}$ & $\begin{array}{l}0.0548 \\
(\mathbf{1 . 0 0 )}\end{array}$ & $\begin{array}{c}0.0172 \\
(0.40)\end{array}$ \\
\hline $\mathrm{HF}_{30}$ & $\begin{array}{l}-0.0273 \\
\mathbf{( - 1 . 0 0 )}\end{array}$ & $\begin{array}{c}-0.0393 \\
\mathbf{( - 1 . 0 0 )}\end{array}$ & & $\begin{array}{l}-0.0232 \\
\mathbf{( - 1 . 0 0 )}\end{array}$ & $\begin{array}{l}-0.0063 \\
(-0.80)\end{array}$ & $\begin{array}{l}-0.0472 \\
\mathbf{( - 1 . 0 0 )}\end{array}$ & $\begin{array}{l}-0.0031 \\
(-0.60)\end{array}$ & $\begin{array}{l}-0.0371 \\
\mathbf{( - 1 . 0 0 )}\end{array}$ & $\begin{array}{c}-0.0046 \\
(-0.60)\end{array}$ & $\begin{array}{l}-0.0422 \\
\mathbf{( - 1 . 0 0 )}\end{array}$ \\
\hline $\mathrm{HF}_{30}^{(1)}$ & $\begin{array}{l}-0.0060 \\
(-0.40)\end{array}$ & $\begin{array}{l}-0.0180 \\
(-0.80)\end{array}$ & $\begin{array}{l}0.0213 \\
\mathbf{( 1 . 0 0 )}\end{array}$ & & $\begin{array}{c}0.0169 \\
(0.80)\end{array}$ & $\begin{array}{l}-0.0240 \\
(-\mathbf{1 . 0 0})\end{array}$ & $\begin{array}{l}0.0201 \\
\mathbf{( 1 . 0 0 )}\end{array}$ & $\begin{array}{l}-0.0139 \\
(-\mathbf{1 . 0 0})\end{array}$ & $\begin{array}{l}0.0186 \\
\mathbf{( 1 . 0 0 )}\end{array}$ & $\begin{array}{l}-0.0190 \\
(-\mathbf{1 . 0 0 )}\end{array}$ \\
\hline $\mathrm{HF}_{5}$ & $\begin{array}{l}-0.0205 \\
(-0.80)\end{array}$ & $\begin{array}{l}-0.0326 \\
\mathbf{( - 1 . 0 0 )}\end{array}$ & $\begin{array}{l}0.0067 \\
(0.80)\end{array}$ & $\begin{array}{l}-0.0145 \\
(-0.80)\end{array}$ & & $\begin{array}{c}-0.0409 \\
(\mathbf{- 1 . 0 0 )}\end{array}$ & $\begin{array}{c}0.0032 \\
(0.40)\end{array}$ & $\begin{array}{l}-0.0308 \\
(\mathbf{- 1 . 0 0 )}\end{array}$ & $\begin{array}{l}0.0017 \\
(0.00)\end{array}$ & $\begin{array}{l}-0.0359 \\
(\mathbf{- 1 . 0 0 )}\end{array}$ \\
\hline $\mathrm{HF}_{5}^{(10)}$ & $\begin{array}{c}0.0053 \\
(0.60)\end{array}$ & $\begin{array}{l}-0.0067 \\
(-0.40)\end{array}$ & $\begin{array}{l}0.0326 \\
(\mathbf{1 . 0 0 )}\end{array}$ & $\begin{array}{l}0.0113 \\
\mathbf{( 1 . 0 0 )}\end{array}$ & $\begin{array}{l}0.0259 \\
\mathbf{( 1 . 0 0 )}\end{array}$ & & $\begin{array}{l}0.0440 \\
(\mathbf{1 . 0 0 )}\end{array}$ & $\begin{array}{c}0.0100 \\
(0.60)\end{array}$ & $\begin{array}{l}0.0425 \\
(\mathbf{1 . 0 0 )}\end{array}$ & $\begin{array}{c}0.0050 \\
(0.40)\end{array}$ \\
\hline $\mathrm{HF}_{75}$ & $\begin{array}{l}-0.0276 \\
\mathbf{( - 1 . 0 0 )}\end{array}$ & $\begin{array}{l}-0.0396 \\
\mathbf{( - 1 . 0 0 )}\end{array}$ & $\begin{array}{c}-0.0003 \\
(0.20)\end{array}$ & $\begin{array}{l}-0.0216 \\
(\mathbf{- 1 . 0 0 )}\end{array}$ & $\begin{array}{l}-0.0071 \\
(-0.20)\end{array}$ & $\begin{array}{l}-0.0329 \\
(\mathbf{- 1 . 0 0 )}\end{array}$ & & $\begin{array}{l}-0.0340 \\
(-1.00)\end{array}$ & $\begin{array}{l}-0.0015 \\
(-0.20)\end{array}$ & $\begin{array}{l}-0.0391 \\
\mathbf{( - 1 . 0 0 )}\end{array}$ \\
\hline $\mathrm{HF}_{75}^{(1)}$ & $\begin{array}{c}0.0036 \\
(0.40)\end{array}$ & $\begin{array}{l}-0.0084 \\
(-0.40)\end{array}$ & $\begin{array}{l}0.0309 \\
\mathbf{( 1 . 0 0 )}\end{array}$ & $\begin{array}{l}0.0096 \\
\mathbf{( 1 . 0 0 )}\end{array}$ & $\begin{array}{l}0.0241 \\
\mathbf{( 1 . 0 0 )}\end{array}$ & $\begin{array}{l}-0.0017 \\
(-0.20)\end{array}$ & $\begin{array}{l}0.0312 \\
\mathbf{( 1 . 0 0 )}\end{array}$ & & $\begin{array}{l}0.0325 \\
\mathbf{( 1 . 0 0 )}\end{array}$ & $\begin{array}{c}-0.0051 \\
(0.00)\end{array}$ \\
\hline $\mathrm{HF}_{130}$ & $\begin{array}{l}-0.0262 \\
(\mathbf{- 1 . 0 0 )}\end{array}$ & $\begin{array}{l}-0.0382 \\
(\mathbf{- 1 . 0 0 )}\end{array}$ & $\begin{array}{c}0.0011 \\
(0.20)\end{array}$ & $\begin{array}{l}-0.0202 \\
(\mathbf{- 1 . 0 0 )}\end{array}$ & $\begin{array}{l}-0.0056 \\
(-0.20)\end{array}$ & $\begin{array}{l}-0.0315 \\
(\mathbf{- 1 . 0 0 )}\end{array}$ & $\begin{array}{c}0.0015 \\
(0.00)\end{array}$ & $\begin{array}{l}-0.0297 \\
\mathbf{( - 1 . 0 0 )}\end{array}$ & & $\begin{array}{c}-0.0376 \\
\mathbf{( - 1 . 0 0 )}\end{array}$ \\
\hline $\mathrm{HF}_{130}^{(1)}$ & $\begin{array}{c}0.0021 \\
(0.60)\end{array}$ & $\begin{array}{c}-0.0099 \\
(-0.40)\end{array}$ & $\begin{array}{l}0.0294 \\
\mathbf{( 1 . 0 0 )}\end{array}$ & $\begin{array}{c}0.0081 \\
(0.40)\end{array}$ & $\begin{array}{l}0.0226 \\
\mathbf{( 1 . 0 0 )}\end{array}$ & $\begin{array}{c}-0.0032 \\
(-0.20)\end{array}$ & $\begin{array}{l}0.0297 \\
\mathbf{( 1 . 0 0 )}\end{array}$ & $\begin{array}{c}-0.0015 \\
(0.00)\end{array}$ & $\begin{array}{l}0.0283 \\
\mathbf{( 1 . 0 0 )}\end{array}$ & \\
\hline
\end{tabular}


Table 8: Prediction Errors - Different Frequencies (continued)

Panel B. Realized Beta With Lag-Adjustment

\begin{tabular}{|c|c|c|c|c|c|c|c|c|c|c|}
\hline & HIST & $\mathrm{HIST}^{(1)}$ & $\mathrm{HF}_{30}$ & $\mathrm{HF}_{30}^{(1)}$ & $\mathrm{HF}_{5}$ & $\mathrm{HF}_{5}^{(10)}$ & $\mathrm{HF}_{75}$ & $\mathrm{HF}_{75}^{(1)}$ & $\mathrm{HF}_{130}$ & $\mathrm{HF}_{130}^{(1)}$ \\
\hline Avg. RMSE & 0.1492 & 0.1587 & 0.1343 & 0.1275 & 0.1512 & 0.1377 & 0.1299 & 0.1343 & 0.1307 & 0.1411 \\
\hline HIST & & $\begin{array}{l}-0.0095 \\
(-0.40)\end{array}$ & $\begin{array}{c}0.0149 \\
(0.20)\end{array}$ & $\begin{array}{c}0.0217 \\
(0.80)\end{array}$ & $\begin{array}{c}-0.0020 \\
(0.00)\end{array}$ & $\begin{array}{c}0.0114 \\
(0.40)\end{array}$ & $\begin{array}{c}0.0193 \\
(0.80)\end{array}$ & $\begin{array}{c}0.0149 \\
(0.40)\end{array}$ & $\begin{array}{c}0.0185 \\
(0.60)\end{array}$ & $\begin{array}{c}0.0081 \\
(0.20)\end{array}$ \\
\hline $\mathrm{HIST}^{(1)}$ & $\begin{array}{c}0.0060 \\
(0.40)\end{array}$ & & $\begin{array}{c}0.0244 \\
(0.40)\end{array}$ & $\begin{array}{l}0.0312 \\
\mathbf{( 1 . 0 0 )}\end{array}$ & $\begin{array}{c}0.0075 \\
(0.00)\end{array}$ & $\begin{array}{c}0.0210 \\
(0.40)\end{array}$ & $\begin{array}{c}0.0288 \\
(0.80)\end{array}$ & $\begin{array}{c}0.0244 \\
(0.80)\end{array}$ & $\begin{array}{c}0.0280 \\
(0.60)\end{array}$ & $\begin{array}{c}0.0176 \\
(0.40)\end{array}$ \\
\hline $\mathrm{HF}_{30}$ & $\begin{array}{l}-0.0001 \\
(-0.20)\end{array}$ & $\begin{array}{l}-0.0061 \\
(-0.20)\end{array}$ & & $\begin{array}{l}0.0068 \\
(0.60)\end{array}$ & $\begin{array}{c}-0.0169 \\
(-\mathbf{1 . 0 0 )}\end{array}$ & $\begin{array}{c}-0.0035 \\
(0.00)\end{array}$ & $\begin{array}{c}0.0044 \\
(0.60)\end{array}$ & $\begin{array}{c}-0.0000 \\
(0.00)\end{array}$ & $\begin{array}{c}0.0036 \\
(0.40)\end{array}$ & $\begin{array}{c}-0.0068 \\
(0.00)\end{array}$ \\
\hline $\mathrm{HF}_{30}^{(1)}$ & $\begin{array}{l}-0.0114 \\
(-1.00)\end{array}$ & $\begin{array}{l}-0.0174 \\
(-0.80)\end{array}$ & $\begin{array}{l}-0.0113 \\
(-0.60)\end{array}$ & & $\begin{array}{l}-0.0238 \\
(-0.80)\end{array}$ & $\begin{array}{c}-0.0103 \\
(-0.60)\end{array}$ & $\begin{array}{l}-0.0024 \\
(-0.20)\end{array}$ & $\begin{array}{l}-0.0069 \\
(-0.40)\end{array}$ & $\begin{array}{c}-0.0032 \\
(-0.40)\end{array}$ & $\begin{array}{l}-0.0137 \\
(-0.80)\end{array}$ \\
\hline $\mathrm{HF}_{5}$ & $\begin{array}{c}0.0098 \\
(0.60)\end{array}$ & $\begin{array}{c}0.0038 \\
(0.20)\end{array}$ & $\begin{array}{l}0.0099 \\
(\mathbf{1 . 0 0 )}\end{array}$ & $\begin{array}{c}0.0212 \\
(0.80)\end{array}$ & & $\begin{array}{c}0.0135 \\
(0.40)\end{array}$ & $\begin{array}{c}0.0214 \\
(0.80)\end{array}$ & $\begin{array}{c}0.0169 \\
(0.60)\end{array}$ & $\begin{array}{c}0.0205 \\
(0.80)\end{array}$ & $\begin{array}{c}0.0101 \\
(0.40)\end{array}$ \\
\hline $\mathrm{HF}_{5}^{(10)}$ & $\begin{array}{l}-0.0028 \\
(-0.40)\end{array}$ & $\begin{array}{c}-0.0089 \\
(-0.40)\end{array}$ & $\begin{array}{c}-0.0027 \\
(0.00)\end{array}$ & $\begin{array}{l}0.0085 \\
(0.60)\end{array}$ & $\begin{array}{l}-0.0126 \\
(-0.40)\end{array}$ & & $\begin{array}{l}0.0079 \\
(0.20)\end{array}$ & $\begin{array}{c}0.0034 \\
(0.40)\end{array}$ & $\begin{array}{c}0.0071 \\
(0.20)\end{array}$ & $\begin{array}{c}-0.0034 \\
(-0.20)\end{array}$ \\
\hline $\mathrm{HF}_{75}$ & $\begin{array}{l}-0.0042 \\
(-0.20)\end{array}$ & $\begin{array}{l}-0.0102 \\
(-0.60)\end{array}$ & $\begin{array}{l}-0.0041 \\
(-0.60)\end{array}$ & $\begin{array}{c}0.0072 \\
(0.00)\end{array}$ & $\begin{array}{l}-0.0140 \\
(-0.60)\end{array}$ & $\begin{array}{c}-0.0013 \\
(0.00)\end{array}$ & & $\begin{array}{l}-0.0044 \\
(-0.20)\end{array}$ & $\begin{array}{l}-0.0008 \\
(-0.20)\end{array}$ & $\begin{array}{l}-0.0112 \\
(-0.40)\end{array}$ \\
\hline $\mathrm{HF}_{75}^{(1)}$ & $\begin{array}{c}-0.0045 \\
(-0.20)\end{array}$ & $\begin{array}{l}-0.0105 \\
(-0.60)\end{array}$ & $\begin{array}{c}-0.0044 \\
(0.20)\end{array}$ & $\begin{array}{c}0.0068 \\
(0.20)\end{array}$ & $\begin{array}{c}-0.0143 \\
(-0.80)\end{array}$ & $\begin{array}{l}-0.0017 \\
(-0.20)\end{array}$ & $\begin{array}{l}-0.0004 \\
(-0.20)\end{array}$ & & $\begin{array}{c}0.0036 \\
(0.20)\end{array}$ & $\begin{array}{c}-0.0068 \\
(-0.80)\end{array}$ \\
\hline $\mathrm{HF}_{130}$ & $\begin{array}{l}-0.0034 \\
(-0.40)\end{array}$ & $\begin{array}{l}-0.0094 \\
(-0.60)\end{array}$ & $\begin{array}{l}-0.0033 \\
(-0.80)\end{array}$ & $\begin{array}{c}0.0080 \\
(0.60)\end{array}$ & $\begin{array}{l}-0.0132 \\
(-1.00)\end{array}$ & $\begin{array}{c}-0.0005 \\
(0.00)\end{array}$ & $\begin{array}{c}0.0008 \\
(0.20)\end{array}$ & $\begin{array}{c}0.0011 \\
(0.00)\end{array}$ & & $\begin{array}{l}-0.0104 \\
(-0.40)\end{array}$ \\
\hline $\mathrm{HF}_{130}^{(1)}$ & $\begin{array}{l}-0.0025 \\
(-0.40)\end{array}$ & $\begin{array}{l}-0.0085 \\
(-0.40)\end{array}$ & $\begin{array}{l}-0.0024 \\
(-0.20)\end{array}$ & $\begin{array}{c}0.0089 \\
(0.60)\end{array}$ & $\begin{array}{l}-0.0123 \\
(-0.60)\end{array}$ & $\begin{array}{c}0.0003 \\
(0.00)\end{array}$ & $\begin{array}{l}0.0017 \\
(0.20)\end{array}$ & $\begin{array}{c}0.0020 \\
(0.20)\end{array}$ & $\begin{array}{c}0.0009 \\
(0.20)\end{array}$ & \\
\hline
\end{tabular}

Panel C. Daily Realized Beta

\begin{tabular}{lcccccccccc}
\hline \hline & $\mathrm{HIST}$ & $\mathrm{HIST}$ & $\mathrm{HF}_{30}$ & $\mathrm{HF}_{30}^{(1)}$ & $\mathrm{HF}_{5}$ & $\mathrm{HF}_{5}^{(10)}$ & $\mathrm{HF}_{75}$ & $\mathrm{HF}_{75}^{(1)}$ & $\mathrm{HF}_{130}$ & $\mathrm{HF}_{130}^{(1)}$ \\
\hline Avg. RMSE & 0.1509 & 0.1561 & 0.1491 & 0.1464 & 0.1681 & 0.1588 & 0.1433 & 0.1432 & 0.1432 & 0.1495 \\
\hline \hline HIST & & -0.0052 & 0.0018 & 0.0045 & -0.0172 & -0.0079 & 0.0076 & 0.0077 & 0.0078 & 0.0014 \\
& & $(-0.20)$ & $(0.00)$ & $(0.00)$ & $(-0.80)$ & $(-0.40)$ & $(0.20)$ & $(0.00)$ & $(0.20)$ & $(0.00)$ \\
$\mathrm{HIST}^{(1)}$ & 0.0058 & & 0.0070 & 0.0097 & -0.0120 & -0.0027 & 0.0128 & 0.0129 & 0.0130 & 0.0066 \\
& $(0.20)$ & & $(0.20)$ & $(0.00)$ & $(-0.40)$ & $(-0.40)$ & $(0.20)$ & $(0.20)$ & $(0.20)$ & $(0.00)$ \\
$\mathrm{HF}_{30}$ & 0.0061 & 0.0002 & & 0.0027 & -0.0190 & -0.0097 & 0.0058 & 0.0059 & 0.0060 & -0.0004 \\
& $(0.40)$ & $(0.00)$ & & $(0.20)$ & $\mathbf{( - 1 . 0 0 )}$ & $(-0.40)$ & $(\mathbf{1 . 0 0})$ & $(0.20)$ & $(0.80)$ & $(0.00)$ \\
$\mathrm{HF}_{30}^{(1)}$ & 0.0015 & -0.0043 & -0.0045 & & -0.0217 & -0.0124 & 0.0031 & 0.0032 & 0.0033 & -0.0031 \\
& $(0.00)$ & $(-0.20)$ & $(0.00)$ & & $\mathbf{( - 1 . 0 0 )}$ & $(-0.60)$ & $(0.20)$ & $(0.00)$ & $(0.40)$ & $(0.00)$ \\
$\mathrm{HF}_{5}$ & 0.0171 & 0.0113 & 0.0111 & 0.0156 & & 0.0093 & 0.0248 & 0.0249 & 0.0250 & 0.0186 \\
& $(0.80)$ & $(0.80)$ & $(\mathbf{1 . 0 0})$ & $\mathbf{( 1 . 0 0 )}$ & & $(0.20)$ & $(\mathbf{1 . 0 0})$ & $(\mathbf{1 . 0 0 )}$ & $(\mathbf{1 . 0 0 )}$ & $(0.60)$ \\
$\mathrm{HF}_{5}^{(10)}$ & 0.0187 & 0.0129 & 0.0126 & 0.0172 & 0.0016 & & 0.0155 & 0.0156 & 0.0157 & 0.0093 \\
& $(0.60)$ & $(0.60)$ & $(0.40)$ & $(0.80)$ & $(-0.60)$ & & $(0.80)$ & $(0.60)$ & $(0.80)$ & $(0.60)$ \\
$\mathrm{HF}_{75}$ & 0.0043 & -0.0015 & -0.0017 & 0.0028 & -0.0128 & -0.0144 & & 0.0001 & 0.0002 & -0.0062 \\
& $(-0.20)$ & $(-0.20)$ & $(-0.60)$ & $(0.00)$ & $(-0.60)$ & $(-0.60)$ & & $(0.20)$ & $(0.20)$ & $(-0.20)$ \\
$\mathrm{HF}_{75}^{(1)}$ & 0.0033 & -0.0025 & -0.0028 & 0.0018 & -0.0138 & -0.0154 & -0.0010 & & 0.0000 & -0.0063 \\
& $(0.00)$ & $(0.00)$ & $(-0.20)$ & $(0.00)$ & $(-0.80)$ & $(-0.60)$ & $(0.00)$ & & $(0.00)$ & $(-0.40)$ \\
$\mathrm{HF}_{130}$ & 0.0023 & -0.0036 & -0.0038 & 0.0007 & -0.0148 & -0.0164 & -0.0021 & -0.0010 & $(-0.0064$ \\
$\mathrm{HF}_{130}^{(1)}$ & $(-0.20)$ & $(-0.20)$ & $(-0.80)$ & $(-0.20)$ & $\mathbf{( - 1 . 0 0 )}$ & $(-0.60)$ & $(-0.20)$ & $(0.00)$ & $(-0.20)$ \\
& 0.0072 & 0.0014 & 0.0012 & 0.0057 & -0.0099 & -0.0115 & 0.0029 & 0.0039 & 0.0049 \\
\hline \hline
\end{tabular}



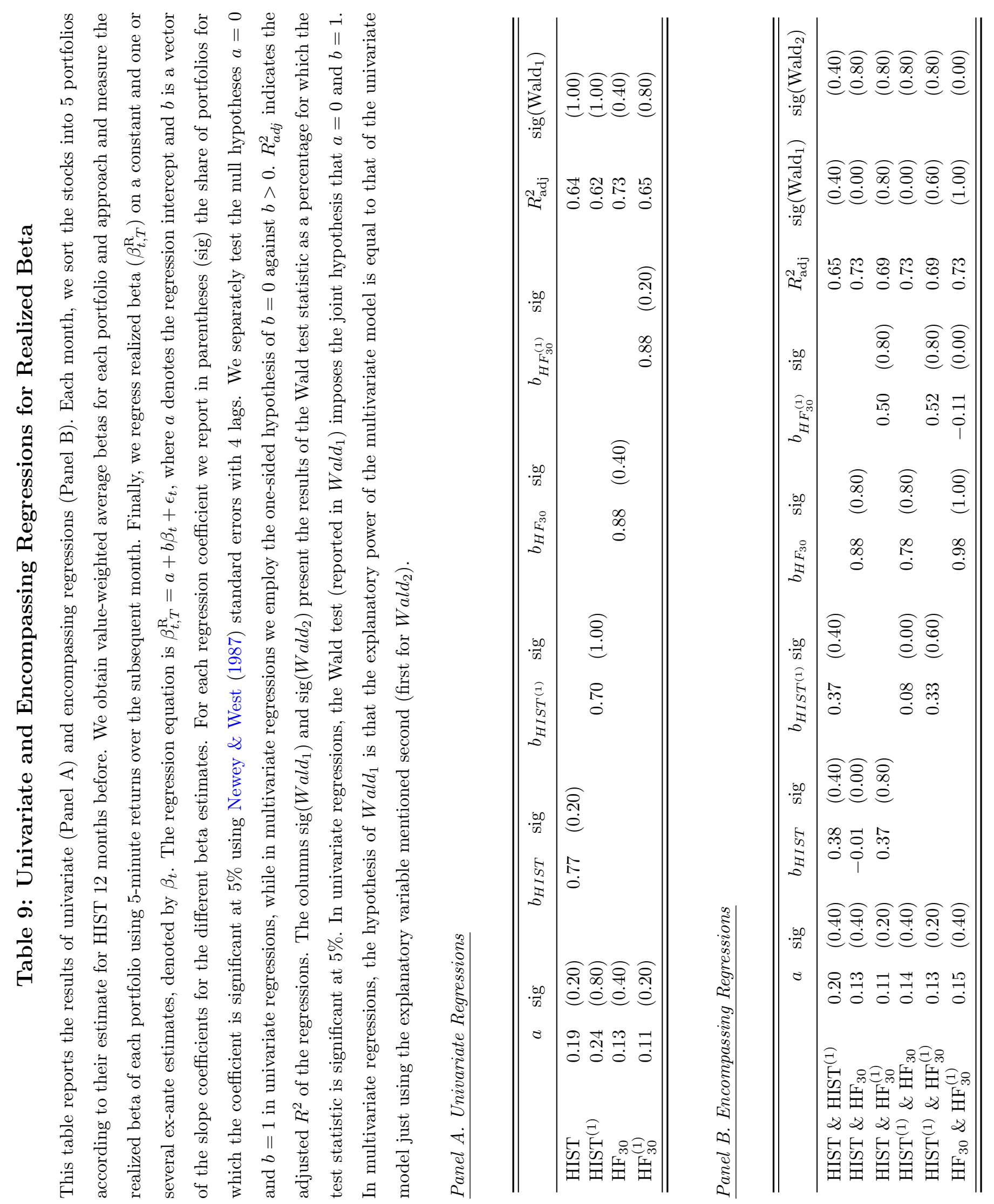


\section{Table 10: Cross-Sectional Predictability}

This table presents results for the cross-sectional predictability of different approaches for 5-minute realized beta over the horizon of 1 month. Panel A reports averages of cross-sectional rank correlations of the approaches with ex-post realized beta in each period. $\rho$ is the average rank correlation coefficient, while $p$-value indicates the corresponding average $p$-value for the null hypothesis of zero correlation. Panel B shows the results of cross-sectional Fama \& MacBeth (1973) regressions, regressing realized beta on exante estimates. We estimate the coefficients and perform the inference following the IV-GMM approach suggested by Kim \& Skoulakis (2016). Const. and Slope denote the time-series averages of the regression intercept and slope coefficients, respectively, while s.e. indicates the corresponding standard errors. The row $R_{a d j}^{2}$ presents the average adjusted $\mathrm{R}^{2} \mathrm{~s}$ of the regressions. ${ }^{*},{ }^{* *}$, and *** indicate significance at the $10 \%, 5 \%$, and $1 \%$ level, respectively.

\section{Panel A. Rank Correlations}

\begin{tabular}{lcccc}
\hline \hline & $\mathrm{HIST}$ & $\mathrm{HIST}^{(1)}$ & $\mathrm{HF}_{30}$ & $\mathrm{HF}_{30}^{(1)}$ \\
\hline$\rho$ & $0.6937^{* * *}$ & $0.6308^{* * *}$ & $0.8034^{* * *}$ & $0.7700^{* * *}$ \\
$(\mathrm{p}$-value $)$ & $(0.0000)$ & $(0.0000)$ & $(0.0000)$ & $(0.0000)$ \\
\hline \hline
\end{tabular}

Panel B. Cross-Sectional Regressions

\begin{tabular}{lcccc}
\hline \hline & $\mathrm{HIST}$ & $\mathrm{HIST}^{(1)}$ & $\mathrm{HF}_{30}$ & $\mathrm{HF}_{30}^{(1)}$ \\
\hline Const. & $-0.0871^{* * *}$ & -0.0264 & $0.0411^{* * *}$ & $-0.0602^{* * *}$ \\
(s.e.) & $(0.0221)$ & $(0.0251)$ & $(0.0125)$ & $(0.0161)$ \\
Slope & $0.9547^{* * *}$ & $0.8352^{* * *}$ & $0.9670^{* * *}$ & $0.9662^{* * *}$ \\
(s.e.) & $(0.1654)$ & $(0.1377)$ & $(0.1106)$ & $(0.1371)$ \\
$R_{\text {adj }}^{2}$ & 0.4903 & 0.3900 & 0.6613 & 0.5984 \\
\hline \hline
\end{tabular}




\section{Table 11: Prediction Errors - MAE}

This table presents the out-of-sample prediction errors of different approaches. Each month, we sort the stocks into 5 portfolios according to their estimate for HIST 12 months before. We obtain valueweighted average betas for each portfolio and approach and measure the realized beta of each portfolio using 5-minute returns over the subsequent month. The first row reports the average MAE across all portfolios. The lowest average error is indicated by italic font. The remainder of the table reports the differences in prediction errors. The upper triangular matrices report the differences in MAE, averaged over all portfolios. Similarly, the lower triangular matrices report the average differences in MedAE. We report the error loss differential between the model [name in row/ and the model [name in column]. The absolute values of the numbers in parentheses indicate the share of portfolios for which the difference is significant at $5 \%$ (e.g., 0.4 indicates that the difference is significant for $40 \%$ of the portfolios). Figures printed in bold indicate that the differences are significant for all portfolios. We test significance with the modified Diebold-Mariano and the Wilcoxon signed rank tests for the upper and lower triangular matrices, respectively. The sign of the number in parentheses indicates the direction of the significant differences.

\begin{tabular}{lcccc}
\hline \hline & $\mathrm{HIST}$ & $\mathrm{HIST}^{(1)}$ & $\mathrm{HF}_{30}$ & $\mathrm{HF}_{30}^{(1)}$ \\
\hline Avg. MAE & 0.1020 & 0.1183 & 0.0703 & 0.0919 \\
\hline \hline HIST & & -0.0162 & 0.0318 & 0.0101 \\
& & $\mathbf{( - 1 . 0 0 )}$ & $\mathbf{( 1 . 0 0 )}$ & $(0.40)$ \\
$\mathrm{HIST}^{(1)}$ & 0.0118 & & 0.0480 & 0.0264 \\
& $\mathbf{( 1 . 0 0 )}$ & & $\mathbf{( 1 . 0 0 )}$ & $\mathbf{( 1 . 0 0 )}$ \\
$\mathrm{HF}_{30}$ & -0.0277 & -0.0395 & & -0.0216 \\
& $(\mathbf{- 1 . 0 0 )}$ & $\mathbf{( - 1 . 0 0 )}$ & & $\mathbf{( - 1 . 0 0 )}$ \\
$\mathrm{HF}_{30}^{(1)}$ & -0.0064 & -0.0181 & 0.0214 & \\
& $(-0.40)$ & $(-0.80)$ & $\mathbf{( 1 . 0 0 )}$ & \\
\hline \hline
\end{tabular}

